Use this template for your ACR conspectus.

Your conspectus must fit on one page.

TO USE:

Select each section of text separately (Title, Author, Affiliation, Text) and type in your text.

\section{If you prefer to copy and} paste existing text into this template, section by section, you must apply the indicated styles to each section.

DO NOT

Select $A$ II and replace with your text-this will remove some needed rules, text, and formatting.

\section{Conspectus Template for ACCOUNTS xems}

NOTE: Since the font used in this template is an approximation of the font used in ACR the line breaks will not match and the final size of your image may be adjusted if more space is needed.

For styles below use only soft returns within the text to break lines. Use hard returns

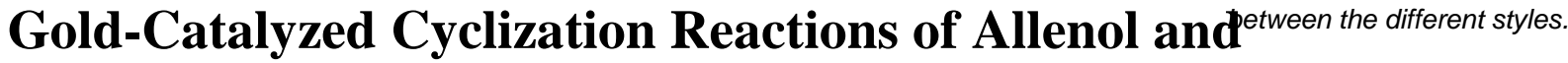
Alkynol Derivatives

\author{
BENITO ALCAIDE ${ }^{* \dagger}$ AND PEDRO ALMENDROS* ${ }^{*}$
}

${ }^{\dagger}$ Grupo de Lactamas y Heterociclos Bioactivos, Departamento de Química Orgánica I, Unidad Asociada al CSIC, Facultad de Química, Universidad Complutense de Madrid, 28040-Madrid, Spain, and ${ }^{\ddagger}$ Instituto de Química Orgánica General, IQOG-CSIC, Juan de la Cierva 3, 28006-Madrid, Spain

RECEIVED ON DATE GOES HERE.
Title Style:

ACRCON_TITLE

Times New Roman Bold 16pt with single line spacing

Author style: ACRCON AUTHORS

Times New Roman 11pt All Caps with single spacing

Affiliation style: ACRCON_AFFILIATION

\section{O N S PECT US}

Times New Roman 9.5pt with sinale line spacing
Text style:

ACRCON_TEXT

Times New Roman

$8 p t$ with exactly 13pt line spacing

Image guidelines. Conspectus images should follow the basic guidelines for all journa images.

For detailed info go to

pubs.acs.org.

Images should be $100 \%$ size (or larger) and 300dpi (or larger)

CMYK tif.

The quality of the graphics depends on the quality of original files. Figures cannot be modified or enhanced by production staff.

Whenever possible, the graphic files furnished by authors by Web

submission are used sc they must be high quality. Images may also be submitted separately but size/shape should be indicated on this template and wrap text fo give a close approximation of how much text will fit.
This Account describes our achievements on gold-catalyzed transformations using allenol and alkynol derivatives. Of these, oxa- and carbo-cyclizations are best known and studied. We have divided those contributions into sections arranged according to the nature of the starting material (allene versus alkyne).

Gold-catalyzed carbocyclizations in allenyl C2-linked indoles, allenyl- $\beta$ lactams and allenyl sugars follow different patterns. Gold-catalyzed cyclization of indole-tethered allenols allows the efficient synthesis of carbazole derivatives. The gold-catalyzed 9-endo carbocyclization of (aryloxy)allenyl-tethered 2azetidinones is in salient contrast to the 5-exo hydroalkylation observed for allenyl sugars.

The unusual preference for the 4-exo-dig cyclization in allene chemistry as well as the rare $\beta$-hydride elimination reaction in gold catalysis, have been illustrated starting from readily available $\alpha$-allenols. Besides, it has been observed in $\gamma$-allenols that a (methoxymethyl)oxy protecting group not only masks an hydroxyl functionality, but also exerts directing effects as a controlling unit in a gold-catalyzed regioselectivity reversal. Our recent work has also led to a combined experimental and computational study on regioselective goldcatalyzed synthetic routes to 1,3-oxazinan-2-ones (kinetically-controlled products) and 1,3-oxazin-2-one derivatives (thermodynamically favored) from easily accessible allenic carbamates.

Direct gold-catalyzed cycloketalization of alkynyldioxolanes as well as aminoketalization of alkynyloxazolidines have been described. Labeling studies and density functional calculations were performed to gain insight into the mechanisms of the bisheterocyclization reactions. We also describe the controlled gold-catalyzed reactions of primary and secondary propargylic hydroperoxides with a variety of nucleophiles including alcohols and phenols, allowing the direct synthesis of $\beta$-functionalized ketones. Computations and ${ }^{18} \mathrm{O}$-labeling experiments reveals various aspects of the controlled reactivity of propargylic hydroperoxides with external nucleophiles under gold catalysis: The mechanism resembles a Meyer-Schuster rearrangement, but notably, the presence and geometry characteristics of the $\mathrm{OOH}$ functional group allow a new pathway to happen, which cannot apply to propargylic alcohols.

Text

cannot go below this red line 


\title{
Gold-Catalyzed Cyclization Reactions of Allenol and Alkynol Derivatives
}

\author{
Benito Alcaide $^{* \dagger}$ and Pedro Almendros ${ }^{* \ddagger}$ \\ ${ }^{\dagger}$ Grupo de Lactamas y Heterociclos Bioactivos, Departamento de Química Orgánica I, Unidad \\ Asociada al CSIC, Facultad de Química, Universidad Complutense de Madrid, 28040-Madrid, \\ Spain \\ ${ }^{\ddagger}$ Instituto de Química Orgánica General, IQOG-CSIC, Juan de la Cierva 3, 28006-Madrid, Spain \\ E-mail: alcaideb@quim.ucm.es; Palmendros@iqog.csic.es
}

\section{Introduction}

Because of its chemical inertness as a bulk metal, chemists working in catalysis were not fascinated by gold until recently. However, the landmark discovery that nano-sized gold [gold(0) nanoparticles] can be an effective catalyst ${ }^{1}$ open up new and exciting transformations. The recent observation that sub-nanosized gold clusters can be exceptionally active as heterogeneous catalysts at room temperature (reaction turnover numbers of $\left.10^{7}\right)^{2}$ will also inspire a great number of discoveries. Little was known about the application of gold complexes [gold(I) and gold(III)] in homogeneous catalysis until Hayashi and then Teles elegantly and independently merged into this field. ${ }^{3,4}$ The last decade has witnessed dramatic growth in the number of reactions catalyzed by gold complexes [gold(I) and gold(III)], notably in its homogeneous catalysis manifestation, ${ }^{5}$ because of their powerful soft Lewis acidic nature. The excellent works from the laboratories of Toste, Hashmi, Corma, Echavarren, Zhang, Fürstner, Malacria, Krause, Gagosz, and many other relevant scientists have well illustrated this point. On the other hand, alkynes and allenes have shown interesting reactivities and selectivities affording complex structures in a limited number of 
steps. ${ }^{6}$ Herein we account our own experience in gold catalysis with a focus on the formation of C$\mathrm{C}$ and $\mathrm{C}-\mathrm{O}$ bonds using allenes and alkynes as starting materials.

\section{Allenes}

Gold-catalyzed carbocyclizations in allenyl C2-linked indoles, allenyl- $\beta$-lactams and allenyl sugars

The carbazole nucleus represents a key molecular motif with widespread occurrence in nature and featuring peculiar biological activities. The indole framework has been very successful in gold catalysis on reacting with alkynes. ${ }^{7}$ The $\mathrm{Au}(\mathrm{I})$-catalyzed cyclization of allenol C2- and C3-linked indoles afforded carbazoles. ${ }^{8}$ A mixture of at least two different products arising from competitive $C$-cyclization versus $O$-cyclization is possible starting from indole-tethered allenols $\mathbf{1 a}$ and $\mathbf{1 b}$. Nicely, substrates $\mathbf{1 a}$ and $\mathbf{1 b}$ gave full conversion to carbazoles $\mathbf{2 a}$ and $\mathbf{2 b}$ in a totally selective fashion (Scheme 1). Worthy of note, despite that gold-based catalysts are well known for their ability to promote the $O$-cyclization of $\alpha$-allenols, ${ }^{9}$ no traces of dihydrofurans were detected. It was also found that this activation mode was also quite successful in the direct cyclization reaction of $\mathrm{NH}$-indolyl allenols (Scheme 1). Thus, it is obvious from the experiments that in our functionalized system competitive heterocyclization processes are not operating. Probably, in our case, the carbazole formation must be driven by the higher stability associated with the aromatic sixmembered carbocycle. It could be inferred that the 6-endo carbocyclization reaction of allenols $\mathbf{1}$ is thermodynamically favored. 
Scheme 1. Gold-catalyzed controlled carbocyclization reaction of allenol C2-linked indoles $1 \mathrm{a}-\mathrm{d}$ to carbazole derivatives $2 a-d$<smiles>[R]C1=CCOC1c1cc2ccccc2n1C</smiles><smiles>[X]C=CC</smiles><smiles>[R]C(=C)C(O)c1cc2ccccc2n1C</smiles><smiles>CCOc1ccc(Cl)cc1</smiles><smiles>[R]c1ccc2c3ccccc3n(C)c2c1</smiles>

1a, $\mathbf{b} \mathrm{R}=\mathrm{Me}, \mathrm{Ph}$

2a, b R $=$ Me, $\mathrm{Ph}(74-89 \%)$<smiles>[R]c1ccn2c(c1)cc1ccccc12</smiles><smiles>[Y][V]</smiles><smiles>[R]C(=C)C(O)c1cc2ccccc2[nH]1</smiles>

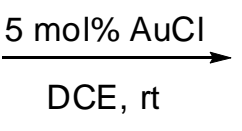<smiles>[R]c1ccc2c(c1)[nH]c1ccccc12</smiles>

1c, $\mathbf{d} \mathrm{R}=\mathrm{Me}, \mathrm{Ph}$ 2c, d R $=\mathrm{Me}, \mathrm{Ph}(58-74 \%)$

A possible pathway for the gold-catalyzed formation of carbazoles 2 from allenol C2-linked indoles 1 may initially involve the formation of a complex 1-AuCl through coordination of the gold chloride to the distal allenic double bond. Next, chemo- and regioselective 6-endo carboauration forms zwitterionic species 3. Attack at the 3-position of the indole occurs as a result of the stability of the intermediate iminium cation type 3 . Loss of $\mathrm{HCl}$ generates neutral species 4 , which followed by protonolysis of the carbon-gold bond and dehydration afforded carbazoles 2 with concurrent regeneration of the gold catalyst (Scheme 2). 
Scheme 2. Mechanistic explanation for the gold-catalyzed carbocyclization reaction of allenol C2linked indoles 1

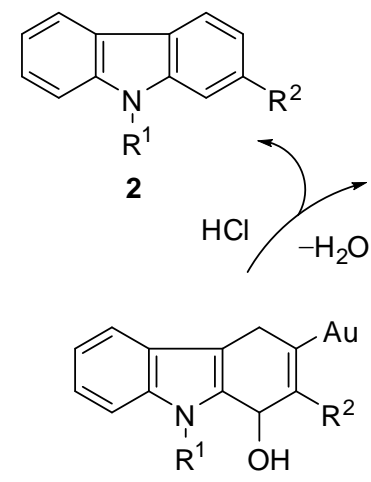

4
$\mathrm{AuCl}$
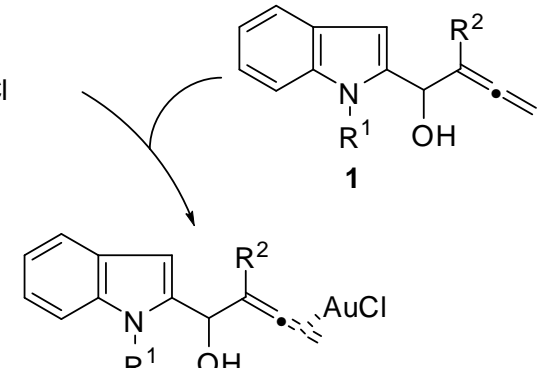

$\mathrm{R}^{1} \mathrm{OH}$

1-AuC

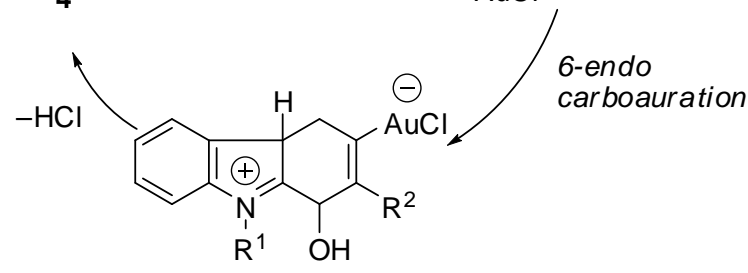

(Aryl)allenol-tethered 2-azetidinones 5 or (aryl)allenol-tethered sugars $\mathbf{6}$, readily prepared from 4-oxoazetidine-2-carbaldehydes or 3-O-(aryl) glucofuranosides, were used as starting materials for the regio- and stereoselective catalytic carbocyclization reaction in the presence of a gold(I) precatalyst. ${ }^{10}$ Interestingly, in contrast to the gold-catalyzed reactions of (aryl)allenoltethered sugars which lead to the corresponding cyclopenta[b]furan core derivatives 8 (hydroalkylation adducts), the reactions of (aryl)allenol-tethered 2-azetidinones under identical conditions gave the nine-membered annulated $\beta$-lactam derivatives 7 (hydroarylation adducts) as the sole products (Scheme 3), through exclusive 9-endo carbocyclization by initial attack of the arene moiety to the distal allene carbon. Thus, it is shown that the outcome of the reaction (9-endo hydroarylation versus formal 5-exo hydroalkylation). Moreover, the mildness of the method allowed the preparation of unusual fused 2-azetidinones without harming the sensitive fourmembered ring. In order to confirm the mechanistic proposal, density functional calculations were performed to gain insight into the mechanism of the previously unknown allenic 9-endo hydroarylation reaction (Figure 1). Our calculations suggest that the reaction starts with the exergonic coordination of the $\mathrm{AuPMe}_{3}{ }^{+}$catalyst to the distal double bond of the allenic moiety of $1 \mathbf{M}\left(\Delta \mathrm{G}_{298}=-9.4 \mathrm{kcal} / \mathrm{mol}\right)$. Then, the 9-endo carbocyclation reaction to produce the nine- 
membered ring tricyclic intermediate $\mathbf{2 M}$ occurs through the transition state $\mathbf{T S 1}$. It can be concluded that the initial 9-endo carbocyclization reaction constitutes the bottle-neck of the process in view of the corresponding endergonicity and relatively high activation barrier. Finally, the reaction ends up with the release of the $\mathrm{AuPMe}_{3}{ }^{+}$catalyst, which is coordinated to the endocyclic $\mathrm{C}=\mathrm{C}$ double bond of $\mathbf{6} \mathbf{M}$, to produce the final tricyclic species $\mathbf{7} \mathbf{M}$.

\section{Scheme 3. Gold-catalyzed carbocyclization reaction of allenyl-tethered arenes 5 and 6}
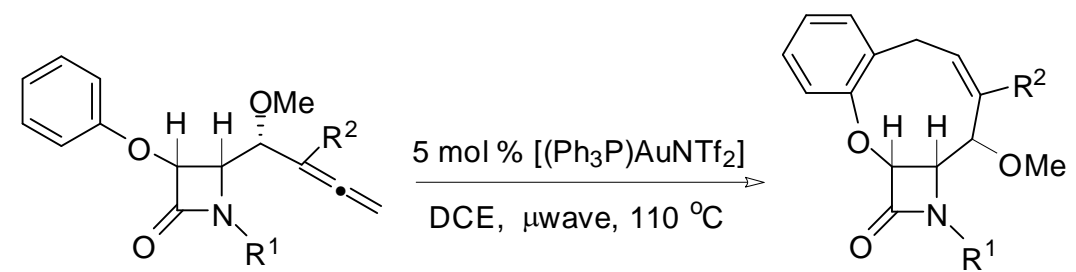

5 a $R^{1}=$ isobutyl, $R^{2}=M e$

$5 b R^{1}=$ isobutyl, $R^{2}=P h$

7 a $(72 \%)$

$7 \mathbf{b}(60 \%)$

7 c $(58 \%)$

$5 c R^{1}=B n, R^{2}=M e$

$5 d R^{1}=B n, R^{2}=P h$

$7 d(69 \%)$

5 e $R^{1}=$ isopropyl, $R^{2}=M e$

5 f $\mathrm{R}^{1}=$ isopropyl, $\mathrm{R}^{2}=\mathrm{Ph}$

7 e $(65 \%)$

$7 f(59 \%)$

$5 \mathrm{~g} \mathrm{R}^{1}=2$-methylallyl, $\mathrm{R}^{2}=\mathrm{Ph}$

7 g $(63 \%)$
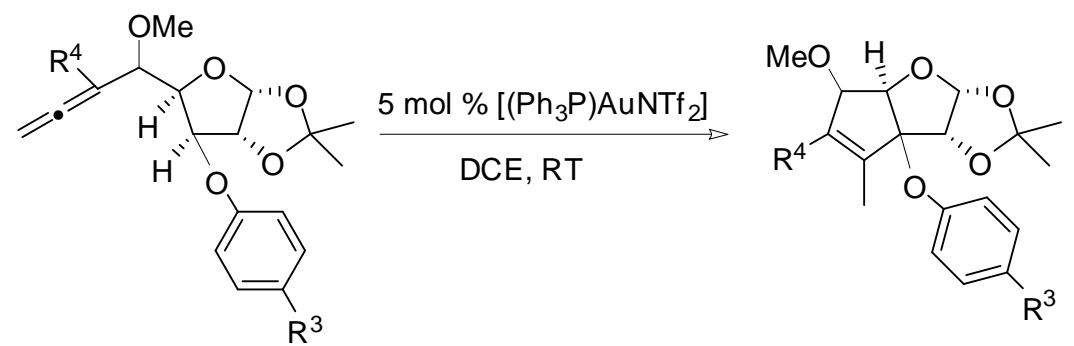

6a $R^{3}=H, R^{4}=M e$

$8 a(46 \%)$

6b $R^{3}=H, R^{4}=E t$

8 b $(34 \%)$

6c $\mathrm{R}^{3}=\mathrm{H}, \mathrm{R}^{4}=\mathrm{BnOCH}_{2}$

$8 c(48 \%)$

$6 d R^{3}=B r, R^{4}=M e$

8d $(35 \%)$

6e $\mathrm{R}^{3}=\mathrm{Br}, \mathrm{R}^{4}=\mathrm{BnOCH}_{2}$

$8 \mathrm{e}(41 \%)$ 
Figure 1. Computed reaction profile for the reaction of allenyl- $\beta$-lactam $1 \mathrm{M}$ and $\left[\left(\mathrm{PMe}_{3}\right) \mathrm{AuNTf}_{2}\right]$ catalyst

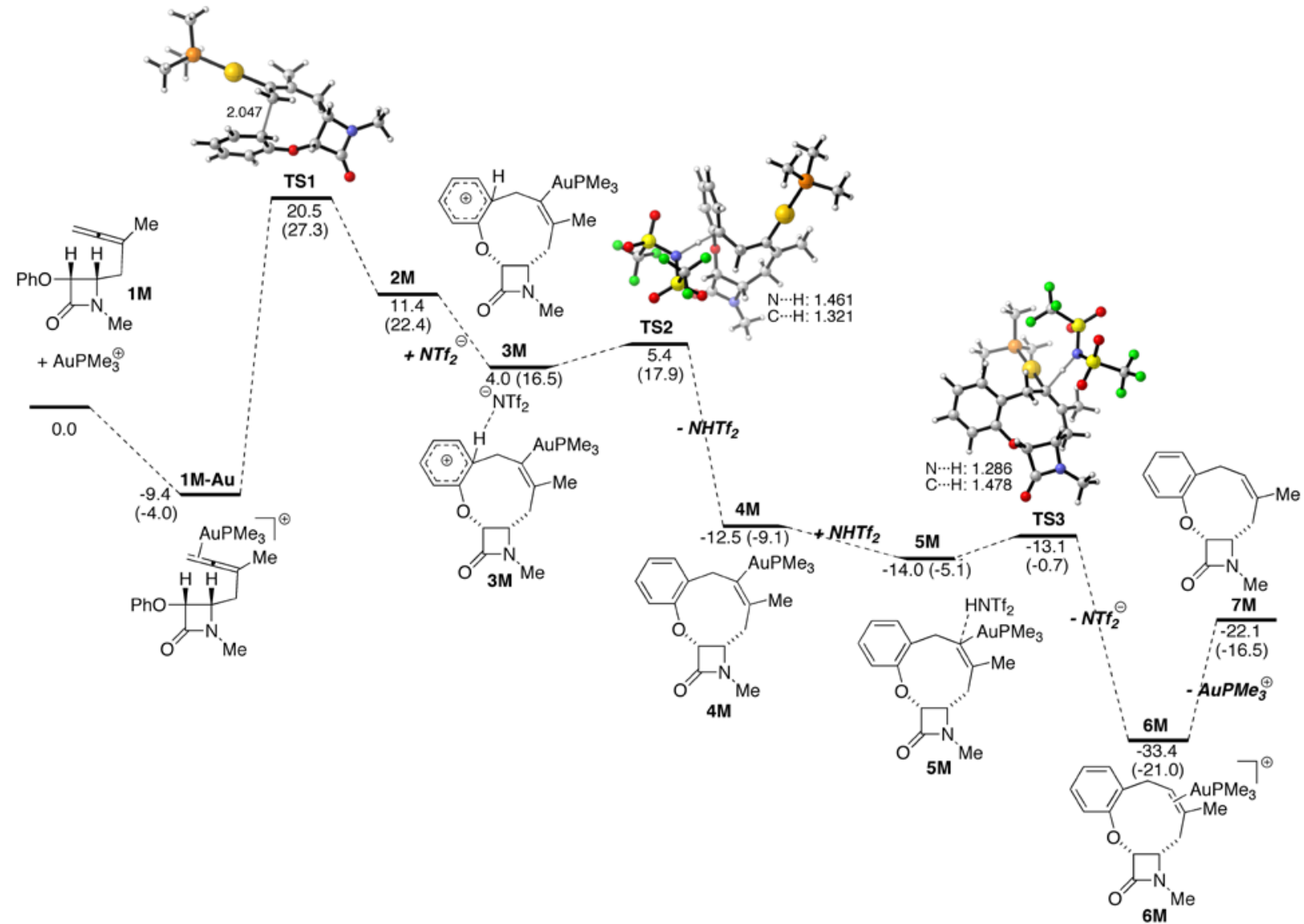

The pathway proposed in Scheme 4 looks valid for the formation of tricycles of type $\mathbf{8}$. It could be presumed that the initially formed gold complex 6-Au(L), through coordination of the gold salt to the distal allenic double bond, undergoes a 1,6-hydride shift (rare transfer of hydride versus normal nucleophilic group attack), giving rise to oxonium species. Intramolecular trapping of the oxonium group by the alkenylgold moiety generates cationic species, through formal 5-exo hydroalkylation. Finally, demetalation yield fused cyclopentenes $\mathbf{8}$ and regenerate the gold catalyst (Scheme 4). 
Scheme 4. Mechanistic explanation for the gold-catalyzed formal 5-exo hydroalkylation of allenyltethered oxyarenes 6<smiles>[R]C1=C(C)[C@]2(O)CCO[C@H]2[C@H]1O</smiles>

8<smiles>CCC(C)C</smiles>

$\oplus$ $\mathrm{NTf}_{2}$ $\mathrm{AuPPh}_{3}$

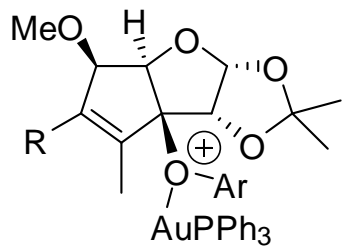<smiles>[R]C(C=CCC(C)C)[C@H](OC)[C@H]1O[C@@H]2OC(C)(C)O[C@@H]2[C@H]1O[CH]</smiles>
$\mathrm{Ph}_{3} \mathrm{PAu}$,<smiles>[R]C=CC=[Ge]</smiles>
6-Au(L) 'H' OAr (1:

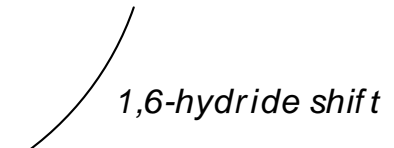

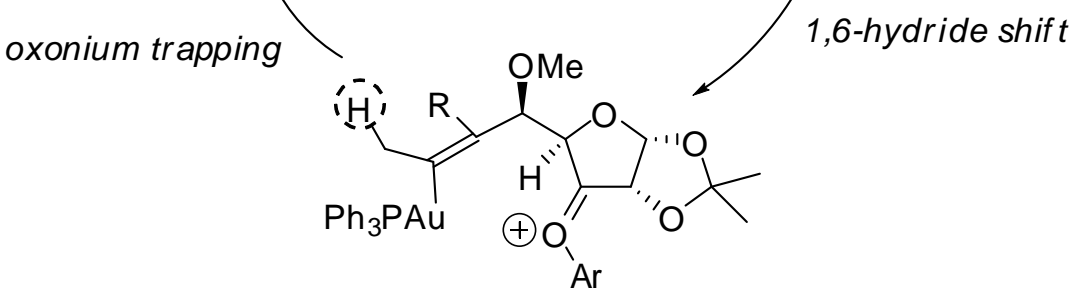

\section{Gold-catalyzed oxycyclization reactions in $\alpha$-allenols and $\gamma$-allenols}

Traditionally, metal-catalyzed cyclizations on $\alpha$-allenols favor a 5-endo-trig pathway. We were attracted to the possibility that a heterocycle different to a five-membered ring could be accessed by variation of the allene substitution. Starting from salicylaldehyde-derived phenyl-substituted allenols $\mathbf{9}$, the gold-catalyzed synthesis of oxetenes $\mathbf{1 0}$ was achieved (Scheme 5). ${ }^{11}$ 
Scheme 5. Synthesis of oxetenes 10 through oxycyclization reaction of $\alpha$-allenols 9 under gold catalysis

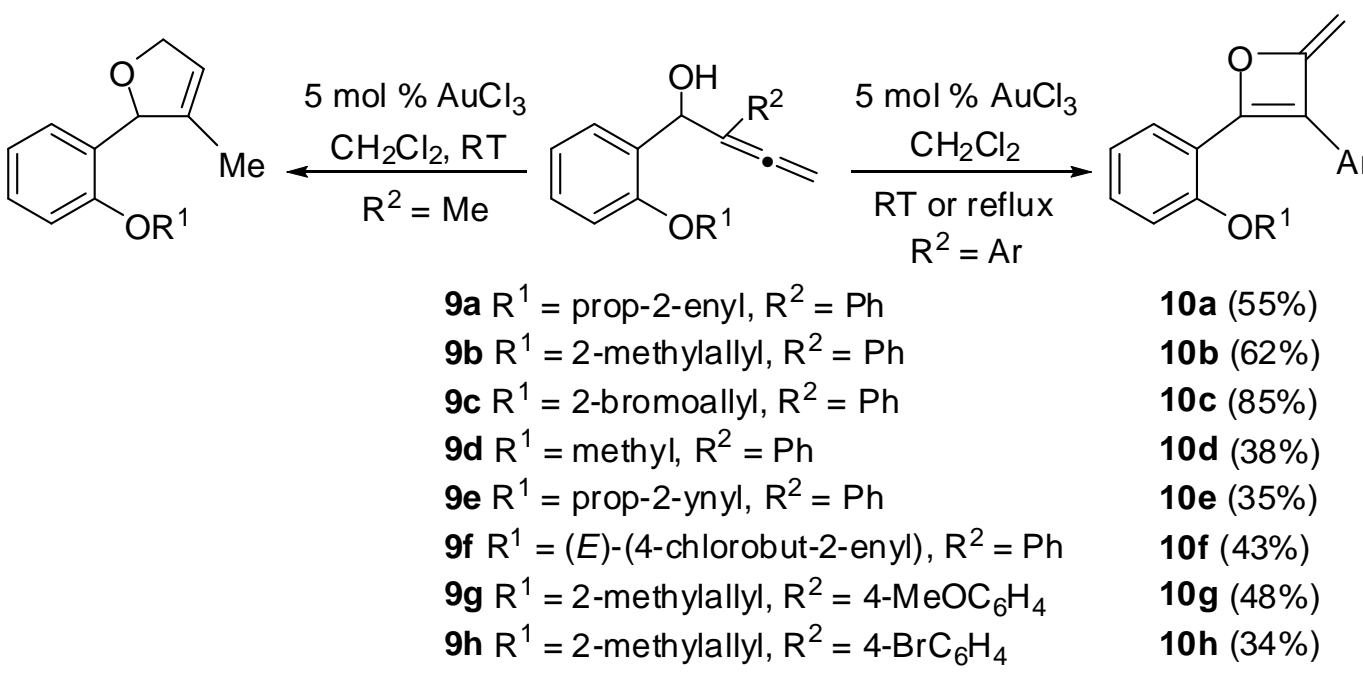

A mechanistic rationale for the gold-catalyzed conversion of aryl-substituted allenols $\mathbf{9}$ into oxetenes $\mathbf{1 0}$ is intricate. It is worth noting that the cyclization affords cycloadducts $\mathbf{1 0}$ from a 4-exodig cyclization/dehydrogenation process instead of that from the usually preferred 5-endo-trig cycloisomerization reaction. The pathway proposed in Scheme 6 looks valid for the formation of products type 10. It could be presumed that the initially formed gold complex 11, through coordination of the $\mathrm{AuCl}_{3}$ to the distal allenic double bond, undergoes an intramolecular attack (rare 4-exo-dig versus normal 5-endo-trig oxyauration) by the hydroxy group, giving rise to the oxetene intermediate 12. Loss of $\mathrm{HCl}$ in intermediate 12 generates neutral species 13, which after 1,3-gold migration ${ }^{12}$ leads to the formation of oxetane species 14. Uncommon $\beta$-hydride elimination ${ }^{13}$ rather than protonolysis of the carbon-gold bond, linked to a reaction of $\mathrm{HCl}$ with the gold hydride would then liberate the oxacycle type $\mathbf{1 0}$ with concomitant regeneration of the catalytic Au(III) salt. 
Scheme 6. Mechanistic explanation for the gold-catalyzed oxycyclization of aryl substituted $\alpha$ allenols 9<smiles>C=C1OC(c2ccccc2OCC)=C1[Al]</smiles><smiles>[R2]c1cc(CC(C)C)ccc1C(O)C(Br)(Br)C=C</smiles>

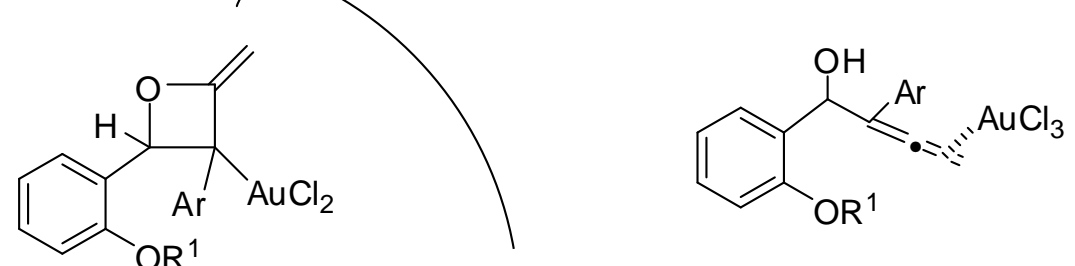

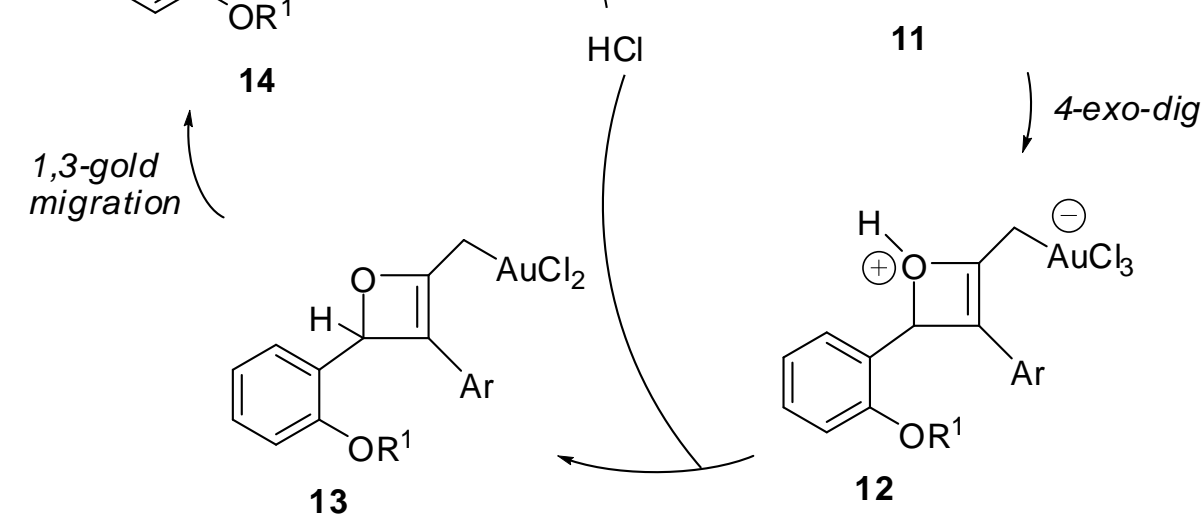

We have accomplished a regiodivergent gold-catalyzed $\mathrm{O}-\mathrm{C}$ functionalization of 2azetidinone-tethered $\gamma$-allenol derivatives. ${ }^{14}$ The reactivity of 2-azetidinone-tethered $\gamma$-allenols toward the regioselective hydroalkoxylation reaction was tested with substrate $15 a\left(R^{1}=B n, R^{2}=\right.$ TBS) by the use of $\mathrm{AuCl}$ and $\mathrm{AuCl}_{3}$ as catalysts. Gratifyingly, it was found that $\mathrm{Au}$ salts were effective as 5-exo selective hydroalkoxylation catalysts, affording bicycle $\mathbf{1 6 a}$. $\mathrm{AuCl}_{3}$ was selected as catalyst of choice because of its superior performance, affording tetrahydrofuran-2-azetidinones 16 in moderate yields (Scheme 7). No regioisomeric products were detected, giving exclusively the fused five-membered oxacycle. 
Scheme 7. Gold-catalyzed cyclization of $\gamma$-allenols for the preparation of five-membered oxacyclic $\beta$ lactams<smiles>[R]OC(C1C(O)C(=O)N1[R])C(C)(C)C=C</smiles>

15
$5 \mathrm{~mol}_{0} \mathrm{AuCl}_{3}$ $\mathrm{CH}_{2} \mathrm{Cl}_{2}, \mathrm{RT}$

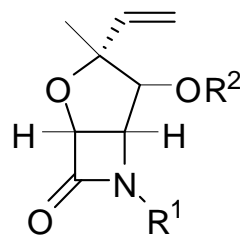

$16(50-58 \%)$

$\mathrm{R}^{1}=\mathrm{Bn}$, allyl; $\mathrm{R}^{2}=\mathrm{TBS}, \mathrm{MeO}-R_{0}^{n}$

A possible pathway for the achievement of bicyclic tetrahydrofurans $\mathbf{1 6}$ from $\gamma$-allenols $\mathbf{1 5}$ may initially involve the formation of a complex $15-\mathrm{AuCl}_{3}$ through coordination of the gold trichloride to the proximal allenic double bond. Next, regioselective 5-exo oxyauration forms zwitterionic species 17. Loss of $\mathrm{HCl}$ followed by protonolysis of the carbon-gold bond of $\mathbf{1 8}$ affords products 16 and regenerates the gold catalyst (Scheme 8).

Scheme 8. Possible catalytic cycle for the gold-catalyzed cyclization of $\gamma$-hydroxyallenes 15

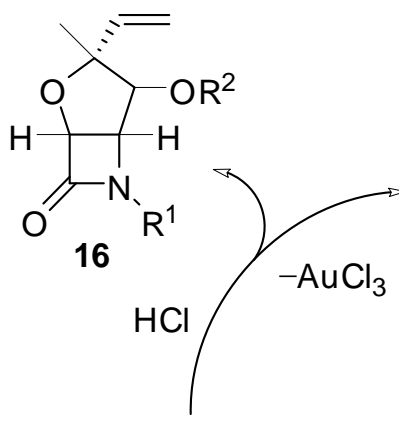

$\mathrm{Cl}_{2} \mathrm{Au}$<smiles>[R]O[C@H]1[C@@H](C)O[C@H]2C(=O)N([R1])[C@@H]21</smiles>

18<smiles>[R2]C([C@H]1[C@@H](O)C(=O)N1[R1])C(C)(C)C=C</smiles>

15

$\mathrm{AuCl}_{3}$<smiles>CCC(C)C</smiles><smiles>[R2]C(C1C(O)C(=O)N1[R])C(C)(C)C(C)(Cl)Cl</smiles>

15- $-\mathrm{AuCl}_{3}$

5-exo

oxyauration<smiles>C[Hg]Cl</smiles>

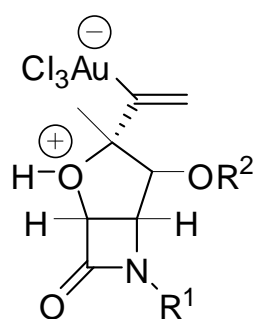

17 
Figure 2. Free energy profile $\left[\mathrm{kcal} \mathrm{mol}^{-1}\right]$ for the transformation of $\gamma$-allenol I into the tetrahydrofuran type 16

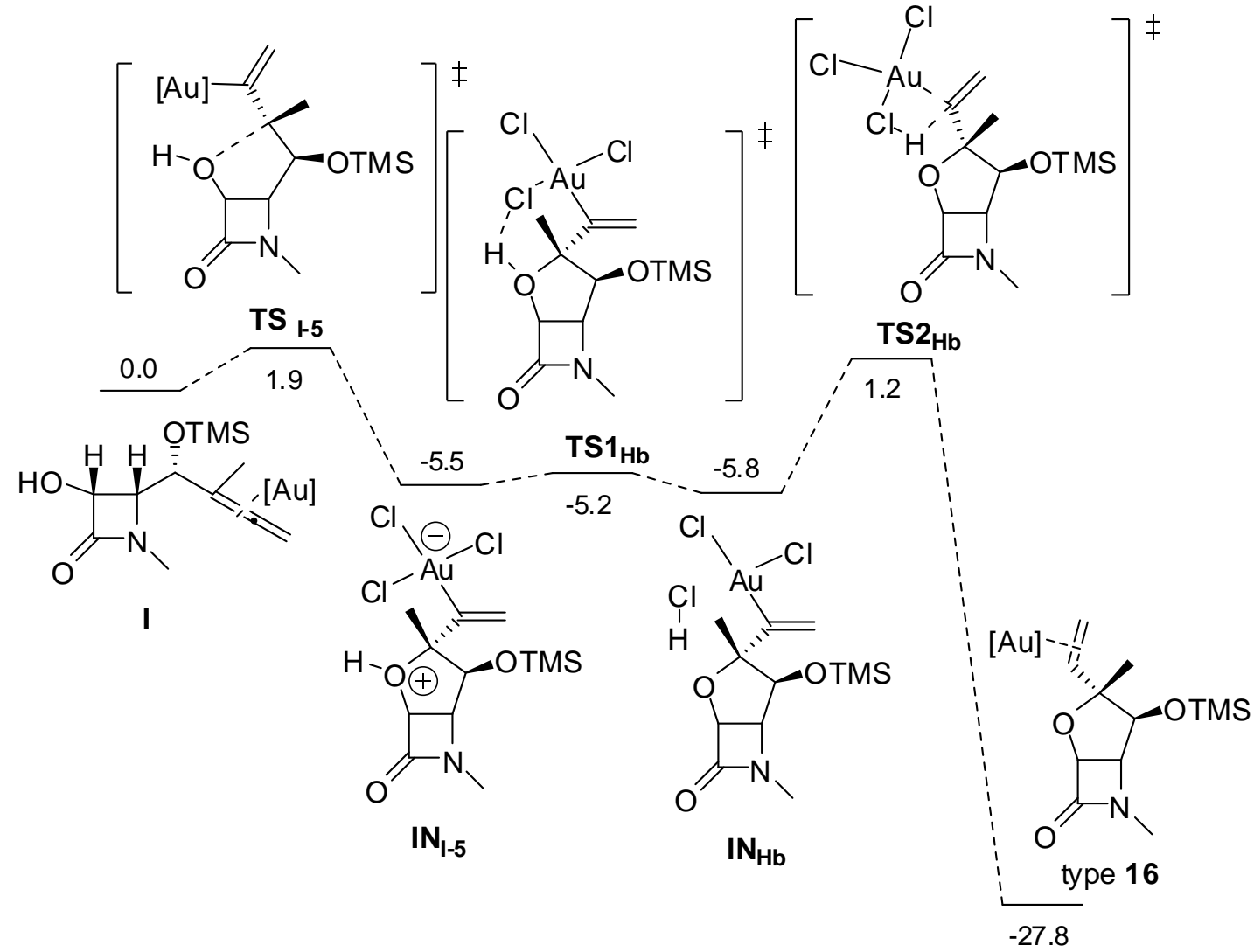

A computational study for the above heterocyclization has been carried out. ${ }^{15}$ Density functional theory (DFT) calculations have been carried out at the PCM-M06/def2SVP//B3LYP/def2-SVP level. The Au(III)-catalyzed cyclization of the model system $\gamma$-allenol I (Fig. 2) takes place regio- and stereoselectively through a 5-exo hydroalkoxylation because of a kinetic preference governed by electronic and steric factors. The results in Figure 2 clearly point to the stepwise mechanism as the most likely route. Therefore, the stepwise path is predicted to be considerably favored over the concerted path, which hence can be ruled out as operative. Overall, the 1,3-H shift is a strongly exothermic process, pointing to a somewhat irreversible character.

Having found a solution for the 5-exo selective hydroalkoxylation, it was next examined the possibility of tuning the regioselectivity in the heterocyclization of $\gamma$-allenol derivatives. Taking into account the sensitivity of the MOM group to acidic conditions, it was decided to see if (methoxymethyl)oxy substitution may had beneficial impact on the above cyclization reactions. 
Thus, it was tested if the metal-catalyzed preparation of bicycles $\mathbf{1 6}$ can be directly accomplished from MOM protected $\gamma$-allenol derivatives 19. Worthy to note that when allenic MOM ethers 19 were treated with $\mathrm{AuCl}_{3}$, the 5-exo mode was completely reverted to a 7-endo cyclization to afford bicycles 20 in fair yields (Scheme 9). ${ }^{14}$ It seems that the reactivity in this type of Au(III)-catalyzed reactions is determined by the presence or absence of a methoxymethyl protecting group at the $\gamma$ allenol oxygen atom, as the free $\gamma$-allenols 15 gave 5-exo hydroalkoxylation, while MOM protected $\gamma$-allenol derivatives 19 exclusively underwent a 7-endo oxycyclization. Thus, it has been demonstrated that regioselectivity control in the metal-catalyzed $\mathrm{O}-\mathrm{C}$ functionalization of $\gamma$ allenols can be achieved through the nature of the $\gamma$-allenol (free versus protected).

Scheme 9. Gold-catalyzed cyclization of MOM-protected $\gamma$-hydroxyallenes for the preparation of seven-membered oxacyclic $\beta$-lactams

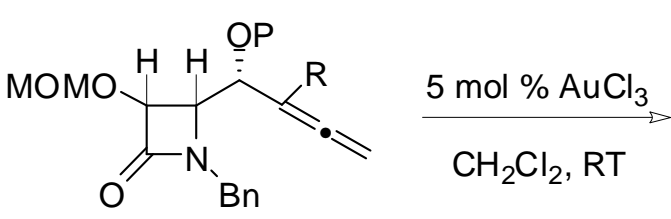

19a $\mathrm{P}=4-\mathrm{MeOC}_{6} \mathrm{H}_{4} \mathrm{CO}, \mathrm{R}=\mathrm{Me}$

19b $\mathrm{P}=4-\mathrm{BrC}_{6} \mathrm{H}_{4} \mathrm{CO}, \mathrm{R}=\mathrm{Me}$

19c $\mathrm{P}=4-\mathrm{MeOC}_{6} \mathrm{H}_{4} \mathrm{CO}, \mathrm{R}=\mathrm{Ph}$

19d $\mathrm{P}=\mathrm{MeCO}, \mathrm{R}=\mathrm{Ph}$

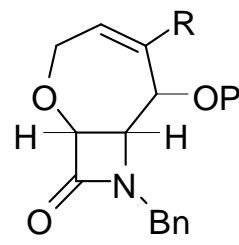

$20 \mathrm{a}(45 \%)$

$20 \mathrm{~b}(58 \%)$

20c $(62 \%)$

20d $(75 \%)$

The pathway proposed in Scheme 10 looks valid for the formation of products $\mathbf{2 0}$ from MOM protected $\gamma$-allenol derivatives 19. It could be presumed that the initially formed allenegold complex 19- $\mathrm{AuCl}_{3}$ undergoes an intramolecular attack (7-endo versus 5-exo oxyauration) by the (methoxymethyl)oxy group, giving rise not to species $\mathbf{2 1}$ but to the tetrahydrooxepine intermediate 22. Protonolysis of the carbon-gold bond linked to an elimination of methanol and formaldehyde would then liberate the bicycle type $\mathbf{2 0}$ with concomitant regeneration of the Au(III) species. Probably, the proton in the last step of the catalytic cycle comes from the trace amount of water present in the solvent or the catalyst. In the presence of MOM group, 5-exo cyclization falters. As calculations reveals, 5-exo oxyauration via $\mathbf{2 1}$ is restricted by the steric hindrance between the (methoxymethyl)oxy group and the substituents at the quaternary stereocenter. ${ }^{15}$ 
Scheme 10. Possible catalytic cycle for the gold-catalyzed cyclization of MOM protected $\gamma$-allenol derivatives 19

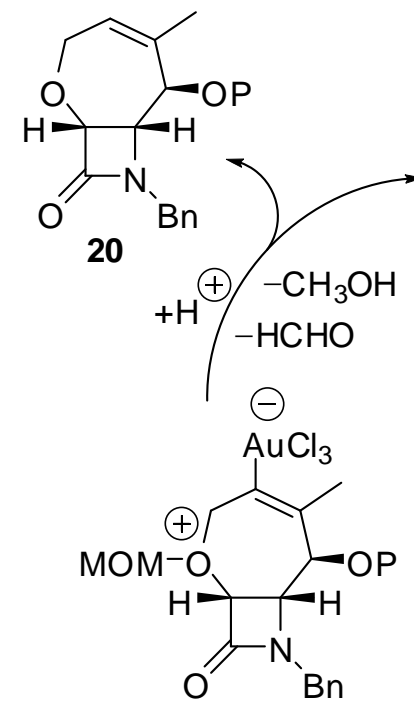

22
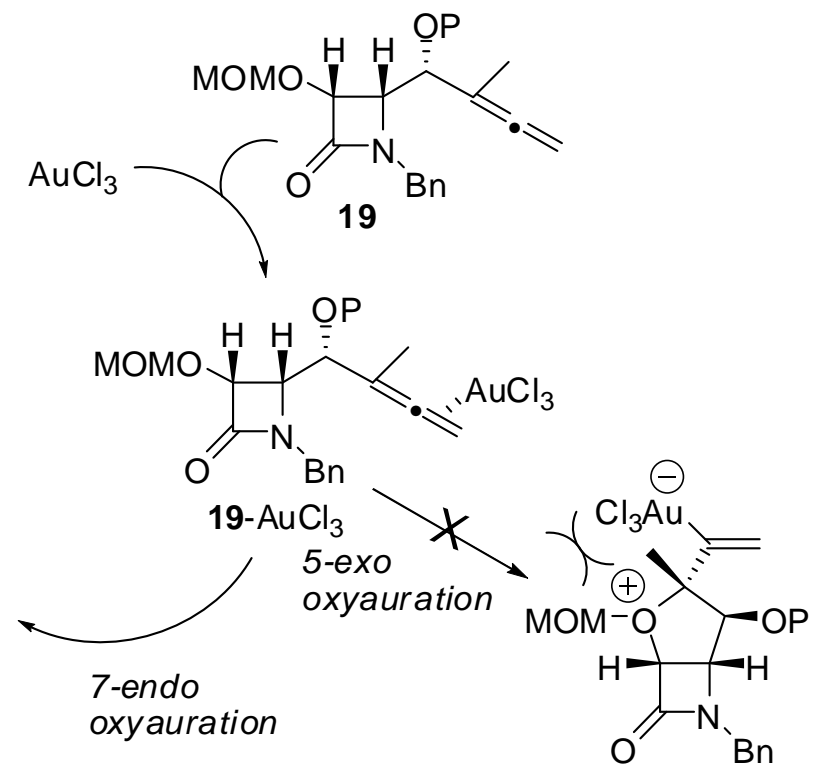

21

The reactions of 3-allenyl 3-hydroxyoxindoles with a variety of halogenated reagents in the presence of catalytic amounts of precious metal salts have been explored. ${ }^{16}$ The kind of functionalization is substrate and reaction conditions dependent: $\mathrm{AuCl}_{3}$ in the presence of NBS afforded as major adducts quinoline-2,3-diones, $\mathrm{AuCl}_{3}$ in the presence of $\mathrm{I}_{2} / \mathrm{PhI}(\mathrm{OAc})_{2}$ favors the formation of spirocyclic iododihydrofurans, whereas $\mathrm{AuCl}_{3}$ in the presence of $\mathrm{IPy}_{2} \mathrm{BF}_{4}$ gives as major product a ring expansion adduct. An interesting case was the reaction of the allene-derived oxindole 23 because the addition of a catalytic amount of $\mathrm{AuCl}_{3}$ completely suppressed the rearrangement reaction, giving instead the corresponding spirocyclic 5-bromooxindole $\mathbf{2 4}$ as the sole product (Scheme 11). Thus, it was shown for the first time that it is possible to use a single gold salt for performing two very different and independent transformations, namely, $\mathrm{C}-\mathrm{O}$ and $\mathrm{C}-$ halogen bond formations, ${ }^{17}$ in a single reaction sequence. 
Scheme 11. Gold-catalyzed simultaneous oxycyclization/bromination reactions of allenic oxindole 23<smiles>C=C(I)C1(C)C(=O)C(=O)N(C)c2ccccc21</smiles>

$(22 \%)$<smiles>CC1=C(I)COC12C(=O)N(C)c1ccc(I)cc12</smiles>

$(42 \%)$

$5 \mathrm{~mol} \% \mathrm{AuCl}_{3}$

$\mathrm{Phl}(\mathrm{OAc})_{2}$

$\mathrm{CH}_{2} \mathrm{Cl}_{2}, \mathrm{RT}$<smiles>C=C(Br)C1(C)C(=O)C(=O)N(C)c2ccccc21</smiles>

$(81 \%)$

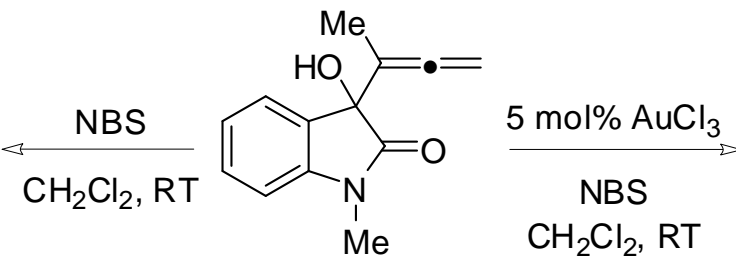

23<smiles>CC1=CCOC12C(=O)N(C)c1ccc(Br)cc12</smiles>

24 (93\%)

$5 \mathrm{~mol}_{0} \mathrm{AuCl}_{3}$

$\mathrm{IPy}_{2} \mathrm{BF}_{4}$

$\mathrm{CH}_{2} \mathrm{Cl}_{2}, \mathrm{RT}$<smiles>C=C(I)C1(C)C(=O)C(=O)N(C)c2ccccc21</smiles>

(49\%)<smiles>CC1=C(I)COC12C(=O)N(C)c1ccccc12</smiles>

(18\%)

Mechanistically, this gold-catalyzed access to spirocyclic bromooxindole $\mathbf{2 4}$ might proceed in a tandem sequence involving as the first step the formation of complex $\mathbf{2 5}$ through coordination of gold trichloride to the distal allenic double bond of $\alpha$-allenol 23. Next, regioselective 5-endo oxyauration forms zwitterionic intermediate 26, which after loss of $\mathrm{HCl}$ generate neutral species 27. Protonolysis of the carbon-gold bond of $\mathbf{2 7}$ liberates adduct $\mathbf{2 8}$, releasing the gold catalyst into the first catalytic cycle (Scheme 12). Next, spirocyclic oxindole $\mathbf{2 8}$ enter the second catalytic cycle, which is also gold-catalyzed, generating zwitterionic species 29 by formation of a C-Au bond in an electrophilic substitution fashion. Subsequent loss of $\mathrm{HCl}$ would regenerate the aromatic ring and would form the neutral arylgold(III) species 30. Nucleophilic attack of the arylgold species $\mathbf{3 0}$ to $\mathrm{N}$ - 
bromosuccinimide liberates bromoadduct $\mathbf{2 4}$ and succinimide with concomitant regeneration of the gold catalyst, closing the second catalytic cycle (Scheme 12).

Scheme 12. Mechanistic explanation for the $A u(I I I)-c a t a l y z e d$ arene bromination/spirocyclization reaction sequence of 3-allenyl 3-hydroxyindolin-2-one 23

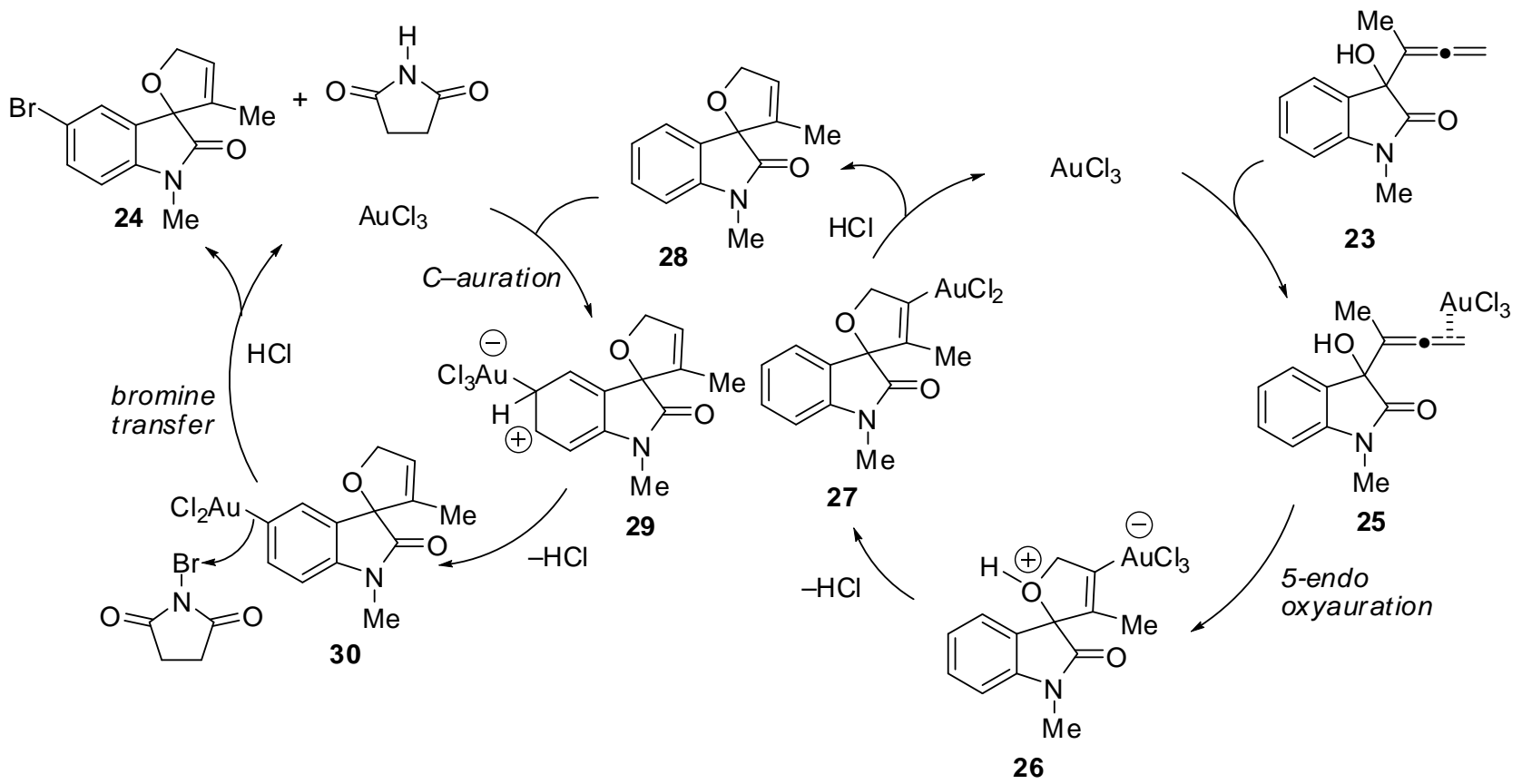

\section{Gold-catalyzed oxycyclization reactions of allenic carbamates}

1,3-Oxazin-2-ones are both biologically relevant compounds as well as valuable intermediates in organic synthesis. ${ }^{18}$ While the synthesis of oxazinones from N-Boc-(3-butyn)-1amines has been established, ${ }^{19}$ the gold-catalyzed cyclization of N-Boc-allenes with the aim of establishing a protocol for the synthesis of 1,3-oxazin-2-one derivatives in which the carbamate group should serve as the source of $\mathrm{CO}_{2}$ has only been examined recently. ${ }^{20}$ We employed three different gold salts in our initial screening of catalysts for a model system allenic carbamate. Initially, the use of $\mathrm{AuCl}_{3}$ and $\mathrm{AuCl}$ were tested, but both failed to catalyze the reaction. Fortunately, we found that $\left[\mathrm{AuClPPh}_{3}\right] / \mathrm{AgOTf}$ was an excellent catalyst for our purpose. The reaction of allenic carbamates $\mathbf{3 1}$ at room temperature afforded 3-benzyl-6-methylene-1,3oxazinan-2-ones 32 bearing an exocyclic double bond as the sole product (Scheme 13). Adding a catalytic amount of Brønsted acid (PTSA) into the reaction system did slightly improve the yield of 32. Solvent screening demonstrated that dichloromethane was the best election in the reaction. 
Interestingly, starting from allenic carbamates $\mathbf{3 1}$ and performing the reaction in dichloromethane at $130{ }^{\circ} \mathrm{C}$, a series of 6-methyl-3-substituted-3,4-dihydro-2H-1,3-oxazin-2-ones 33 were exclusively formed (Scheme 13). The observed regioselectivity is worthy of note, because under our reaction conditions only 1,3-oxazinan-2-ones 32 (arising from 6-endo-dig cyclization) or 3,4dihydro-2H-1,3-oxazin-2-ones 33 (arising from 6-exo-dig cyclization) were achieved, with the nucleophilic oxygen attacking the central allene carbon atom in each case. This is an interesting result, because the available examples on related metal-catalyzed allene heterocyclizations usually lead to 5-exo-trig cyclization; only Hashmi et al. have recently reported an attack at the central position of the allene in allenylamides. ${ }^{21}$ Thus, it is possible to suppress the formation of the 1,3oxazinan-2-one ring by performing the reaction at higher temperature, yielding the 1,3-oxazin-2one as the exclusive product. A general trend can be deduced on the basis of these results: heterocycle $\mathbf{3} 3$ is the thermodynamically controlled product while heterocycle $\mathbf{3 2}$ is the kinetically controlled product.

Scheme 13. Controlled oxycyclization reactions of allenic carbamates 31 to 1,3-oxazinan-2-ones 32 and 1,3-oxazin-2-ones 33 under selective gold-catalyzed conditions ${ }^{a}$ 
<smiles>[R]CN1CCC(=C)OC1=O</smiles>

32a $\mathrm{R}=\mathrm{Ph}(77 \%)$

32b R = PMP (94\%) i)<smiles>[R]CN(CC=C)C(=O)OCc1ccccc1</smiles>

ii)

31a $\mathrm{R}=\mathrm{Ph}$

31b $R=P M P$<smiles>[R]CN1CC=C(C)OC1=O</smiles>

33a $\mathrm{R}=\mathrm{Ph}(70 \%)$

33b $\mathrm{R}=\mathrm{PMP}(70 \%)$<smiles>[R10]C1C(=O)N([R2])[C@@H]1CN1CCC(=C)OC1=O</smiles>
$(+)-32 c(64 \%)$
$(+)-31 c R^{1}=M e, R^{2}=$ PMP
$(+)-33 c(57 \%)$
$(+)-32 \mathrm{~d}(70 \%)$
$(+)-31 d R^{1}=M e, R^{2}=B n$
$(+)-33 d(68 \%)$
$(+)-32 \mathrm{e}(67 \%)$
$(+)-31 e \mathrm{R}^{1}=$ methallyl, $\mathrm{R}^{2}=\mathrm{PMP}$
$(+)-33 \mathrm{e}(66 \%)$<smiles>C=C1CCN(Cc2ccc(CN3CCC(=C)OC3=O)cc2)C(=O)O1</smiles>

$32 f(50 \%)$

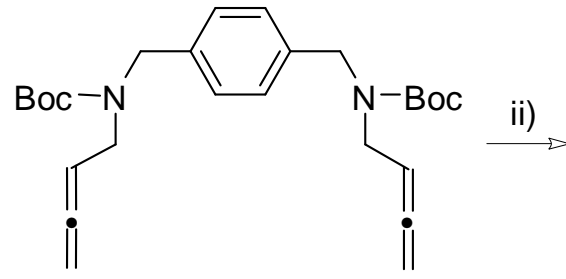

$31 f$

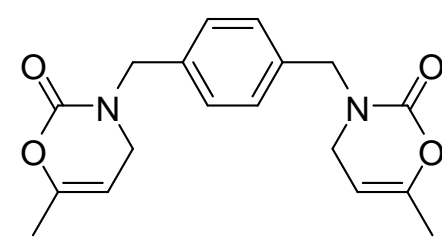

$33 f(54 \%)$<smiles>C=C1CC2CCCN2C(=O)O1</smiles>

$(-)-32 g(82 \%)$<smiles>C=C1Cc2c(Br)c3ccccc3n2C(=O)O1</smiles>

$\mathbf{3 2 h}(58 \%$; ratio $\mathbf{3 2} \mathbf{h}: \mathbf{3} \mathbf{h}=30: 70)$ i)<smiles>C=C=CC1CCCN1C(=O)OC(C)(C)C</smiles>

(-) $-32 \mathrm{~g}$ ii)<smiles>CC1=CC2CCCN2C(=O)O1</smiles>

i)<smiles>C=C=Cc1c(Br)c2ccccc2n1C(=O)OC(C)(C)C</smiles>

$31 \mathrm{~h}$ iii)<smiles>Cc1cc2c(Br)c3ccccc3n2c(=O)o1</smiles>

33h (66\%)

${ }^{a}$ Conditions: (i) 2.5 mol\% [AuCIPPh 3 ], 2.5 mol\% AgOTf, 10 mol\% PTSA, $\mathrm{CH}_{2} \mathrm{Cl}_{2}$, rt. (ii) $2.5 \mathrm{~mol} \%$ [AuClPPh 3 , 2.5 mol\% AgOTf, 10 mol\% PTSA, $\mathrm{CH}_{2} \mathrm{Cl}_{2}$, sealed tube, $130{ }^{\circ} \mathrm{C}$.

A possible pathway for the gold-catalyzed achievement of heterocycles $\mathbf{3 2}$ from allenyltethered carbamates $\mathbf{3 1}$ may initially involve the formation of a complex $\mathbf{3 4}$ through coordination of the gold salt to the proximal allenic double bond. Next, chemo- and regioselective 6-endo-dig oxyauration of the carbamate carbonyl moiety forms species 35. Attack of the carbamate carbonyl 
group occurs as a result of the stability of the intermediate ammonium cation type 35 . Loss of proton linked to 2-methylprop-1-ene release, generates neutral species 36, which followed by protonolysis of the carbon-gold bond affords 6-methylene-1,3-oxazinan-2-ones 32 with concurrent regeneration of the gold catalyst (Scheme 14, left catalytic cycle). In line with the above mechanistic proposal, the easy breakage of the tert-butyl group at species $\mathbf{3 5}$ is essential for the formation of 1,3-oxazinan-2-ones 32. Besides, the replacement of the tert-butyl group in allenic carbamates $\mathbf{3 1}$ by other alkyl functions such as methyl, did not allow the preparation of heterocycles 32. A mechanistic scenario involving the initial coordination of the gold to the distal allenic double bond leading to complex 37, followed by a 6-exo-dig oxyauration is likely for the achievement of 1,3-oxazin-2-ones 33 from allenic carbamates 31 (Scheme 14, right catalytic cycle).

Scheme 14. Mechanistic explanation for the gold-catalyzed oxycyclization reactions of allenic carbamates 31 into 6-methylene-1,3-oxazinan-2-ones 32 or into 3-substituted-3,4-dihydro-2H-1,3oxazin-2-ones 33.

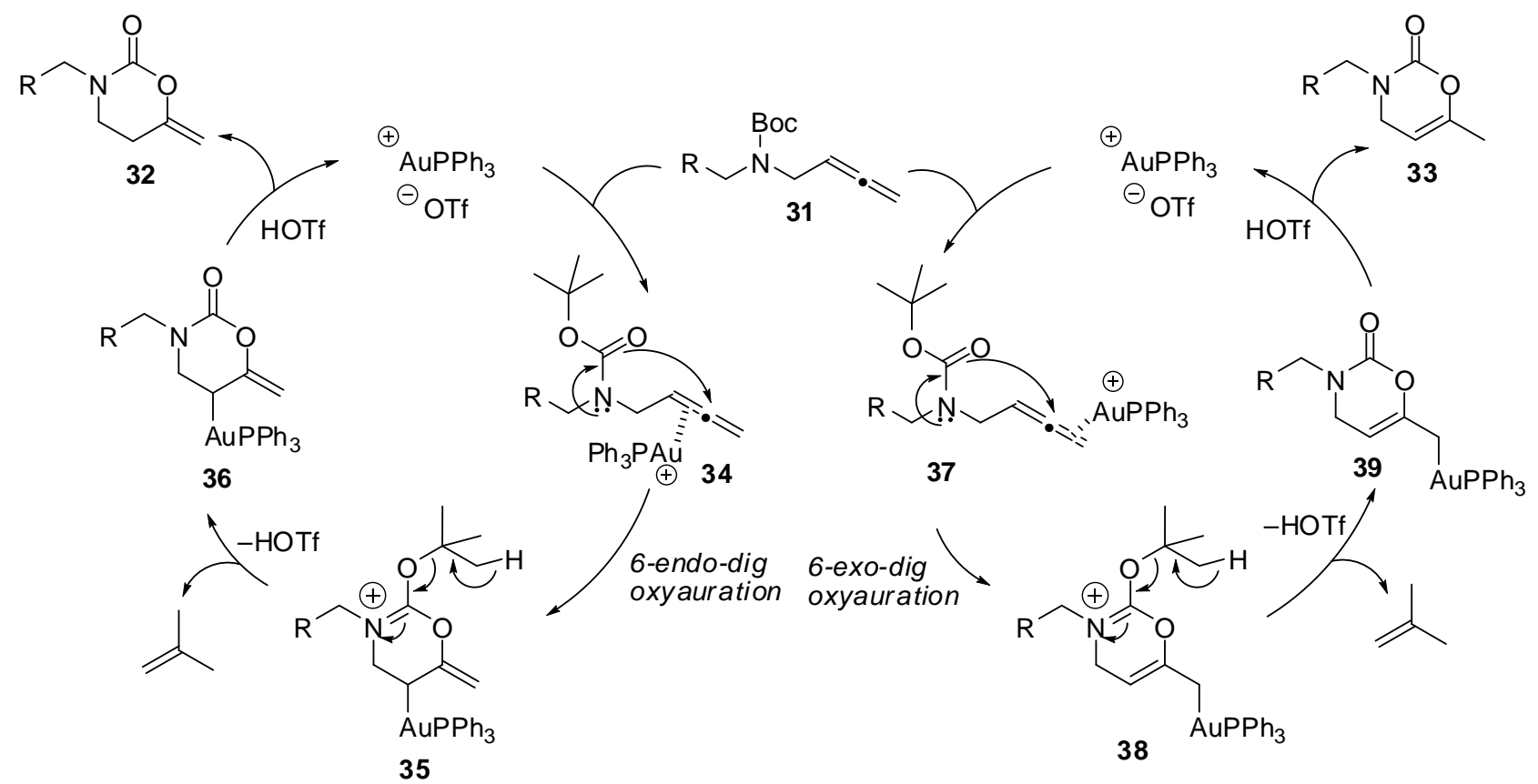

\section{Alkynes}

\section{Gold-catalyzed oxycyclizations of alkynol derivatives}

Activation of alkynes toward attacks by oxygen nucleophiles such as carbonyls, carboxylic acids, and alcohols, is an important $\mathrm{C}-\mathrm{O}$ bond-forming reaction. ${ }^{22}$ In this context, the preparacion 
of fused oxabicyclic $\beta$-lactams using gold catalysis through a tandem oxycyclization/hydroxylation of 2-azetidinone-linked alkynols has been accomplished. ${ }^{23}$ The reaction of 2-azetidinone-tethered bishomopropargylic alcohol $\mathbf{4 0}$ in the presence of catalytic amounts of $\mathrm{AuCl}_{3}$ provided bicycle $\mathbf{4 1}$ in good yield, which may result from a cycloetherification/hydroxylation sequence (Scheme 15). Interestingly, the gold-catalyzed reaction of $\mathbf{4 2}$ possessing a (methoxymethyl)oxy moiety instead the free hydroxyl group, also proceeded smoothly to give the cyclization adduct $\mathbf{4 1}$ albeit in lower yield (Scheme 15). Notably, the observed regioselectivity (5-exo cyclization) was not affected by the presence of a protective group at the hydroxyl moiety. These gold-catalyzed oxycyclizations were successfully extended to trishomopropargylic alcohol 43, yielding the oxycyclization/hydroxylation product 44 with concomitant MOM cleavage (Scheme 15). By contrast, the presence of a phenyl substituent at the terminal alkyne carbon showed a substantial effect on the reactivity, as illustrated by the fact that phenyl alkynol $\mathbf{4 5}$ did afford a complex mixture.

Scheme 15. Synthesis of fused $\beta$-lactam hemiacetals from 2-azetidinone-tethered homopropargylic alcohols under gold-catalyzed conditions.

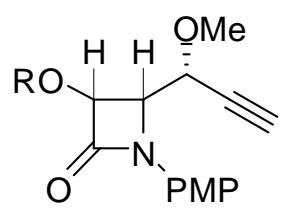

$40 \mathrm{R}=\mathrm{H}$

$42 \mathrm{R}=\mathrm{MOM}$

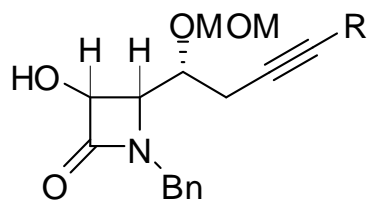

$43 \mathrm{R}=\mathrm{H}$

$45 \mathrm{R}=\mathrm{Ph}$

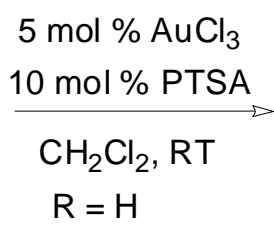

$\mathrm{R}=\mathrm{H}$

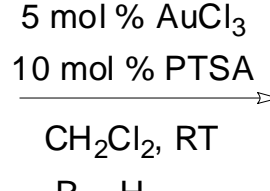

$\mathrm{R}=\mathrm{H}$

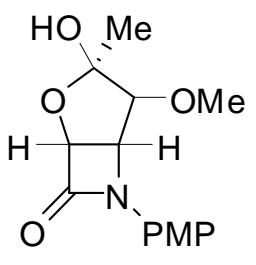

$41(59 \%)$

$41(46 \%)$

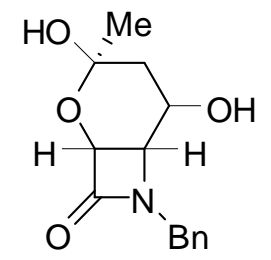

$44(81 \%)$

(a complex mixture was obtained from 45)

A plausible pathway for the achievement of bicyclic tetrahydrofuran $\mathbf{4 1}$ from the methoxymethyl ether 42 may initially involve the formation of a $\pi$-complex 42 - $\mathrm{AuCl}_{3}$ through coordination of the gold trichloride to the alkyne moiety. Next, it could be presumed that the 
initially formed alkynegold complex $42-\mathrm{AuCl}_{3}$ undergoes a regioselective intramolecular attack (5-exo versus 6-endo oxyauration) by the (methoxymethyl)oxy group giving rise to the vinylgold intermediate 46, which linked to an elimination of methanol and formaldehyde would then isomerize to the metalaoxocarbenium species 47. Probably, the water molecule in the third step of the catalytic cycle comes from the trace amount of water present in the solvent or the catalyst. Subsequent nucleophilic attack of water from the less hindered face of intermediate $\mathbf{4 7}$ would form the ate complex 48. Deauration linked to proton transfer liberates adduct $\mathbf{4 1}$ with concomitant regeneration of the $\mathrm{Au}(\mathrm{III})$ species (Scheme 16).

Scheme 16. Mechanistic explanation for the gold-catalyzed oxycyclization reactions of alkynol derivative 42 into fused $\beta$-lactam hemiacetal 41.

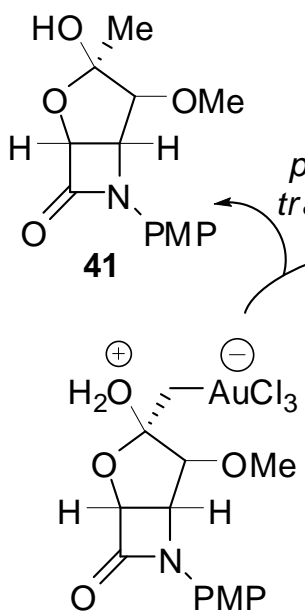

48<smiles>CC(C)O</smiles>

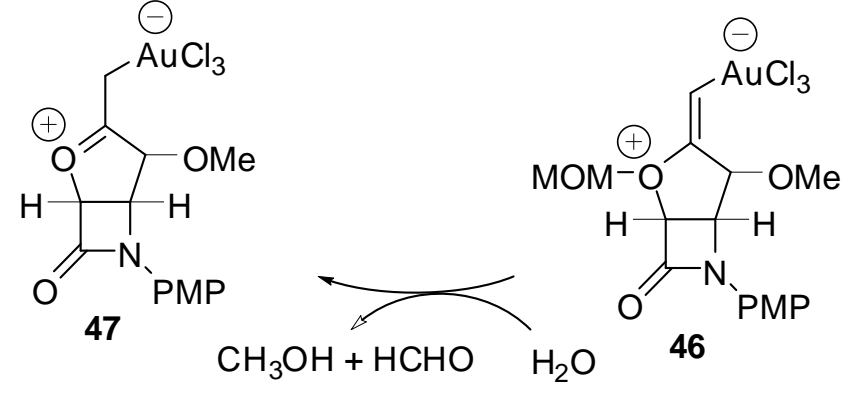

The recently developed gold activation of alkynes toward simultaneous attack by two contiguous oxygen nucleophiles is an important $\mathrm{C}-\mathrm{O}$ bond-forming reaction. ${ }^{24}$ Previous work involves the use of free hydroxy groups (Scheme 17, eq 1). However, the direct bis(oxycyclization) sequence of acetonide-tethered alkynes was missed until we merged into this field. ${ }^{25}$ Using directly 
a dioxolane ring instead of the deprotected 1,2-diol moiety as the starting material, would be a significant breakthrough for metal-catalyzed alkyne-cycloketalization in terms of costeffectiveness. Initial experiments were carried out using (S)-2,2-dimethyl-4-[(prop-2ynyloxy)methyl]-1,3-dioxolane as a model substrate. To optimise the reaction method, different parameters involved in the metal-catalyzed reactions that could affect the formation of the desired product were tested. Nicely, it was found that $\left[\mathrm{AuClPPh}_{3}\right] / \mathrm{AgOTf}$ along with a Brønsted acid (PTSA) in $\mathrm{CH}_{2} \mathrm{Cl}_{2}$ was a competent catalytic system for this purpose. In particular, the transformation was strongly influenced by the presence of water. Having established the optimal reaction conditions, the scope of the methodology was explored by subjecting a range of (prop-2ynyloxy)methyl-tethered dioxolanes $\mathbf{4 9}$ to direct alkyne-cycloketalization and the results are shown in Scheme 17 (eq 2). In both cases (addition of one equivalent of water as well as the presence of large amount of water), the crude reaction mixtures are extremely clean and the acetals are the only products detected. Tolerance toward a variety of substituents (aliphatic, aromatic, and alkynyl groups) on the acetylenic end was demonstrated by obtaining the corresponding enantiopure bridged acetals $\mathbf{5 0}$ in good yields.

Scheme 17. Selective direct bis(oxcyclization) reaction of acetonide-tethered alkynes 1 under golcatalyzed conditions.

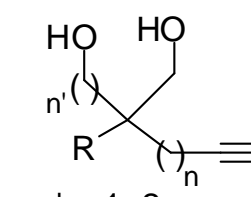

$\mathrm{n}, \mathrm{n}^{\prime}=1,2$

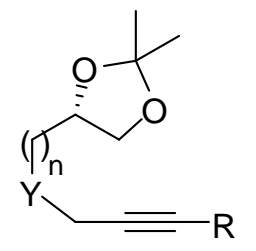

49

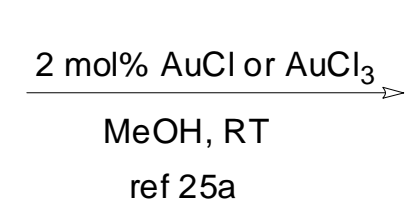

ref $25 a$
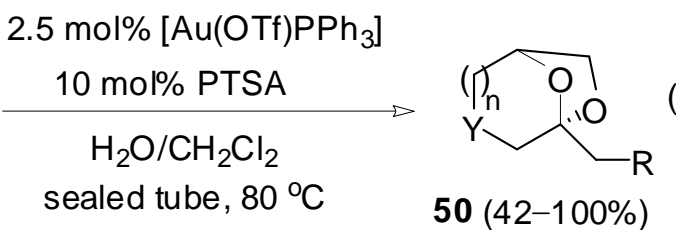

$50(42-100 \%)$

$\mathrm{n}=1,2 ; \mathrm{Y}=\mathrm{O}, \mathrm{NBn}, \mathrm{NCO}_{2} \mathrm{Me} ; \mathrm{R}=\mathrm{H}, \mathrm{D}$, alkyl, aryl, alkynyl

Despite the fact that the intermolecular formation of $\mathrm{N}, \mathrm{O}$-aminals using external $\mathrm{N}$ nucleophiles like anilines had been achieved, ${ }^{26}$ the related direct intramolecular conversion of alkynes into cyclic $\mathrm{N}, \mathrm{O}$-aminals was not described. Therefore, the direct synthesis of $\mathrm{N}, \mathrm{O}$-aminals 
from oxazolidine-derived alkynes emerged as an attractive transformation to develop. Under the optimized reaction conditions used for the preparation of bridged acetals $\mathbf{5 0}$, the catalytic protocol in gold for oxazolidine-tethered alkynes 51 and 52 was investigated. By examining the influence of the $\mathrm{R}$ substituents on the alkyne side chain, it was found that substrates $\mathbf{5 1}$ and $\mathbf{5 2}$ bearing hydrogen, aryl, heteroaryl, or alkyl groups were smoothly transformed into bridged bicyclic aminals 53 and 54 in reasonable yields (Scheme 18). ${ }^{27}$

Scheme 18. Controlled N,O-cycloaminalization reaction of alkynyloxazolidines 51 and 52 under goldcatalyzed conditions.

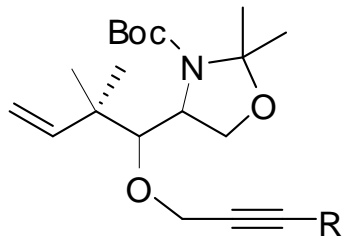

51a $\mathrm{R}=\mathrm{H}$

$51 b \mathrm{R}=\mathrm{Me}$

$51 \mathrm{c} R=\mathrm{Ph}$

51d $R=2-$ pyridyl

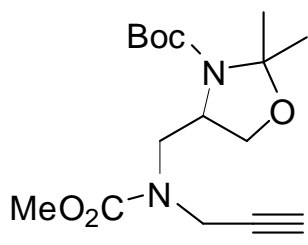

52
$2.5 \mathrm{~mol} \%\left[\mathrm{AuClPPh}_{3}\right], 2.5 \mathrm{~mol} \% \mathrm{AgOTf}$

$10 \mathrm{~mol} \%$ PTSA, $100 \mathrm{~mol} \% \mathrm{H}_{2} \mathrm{O}$

$\mathrm{CH}_{2} \mathrm{Cl}_{2}$, sealed tube, $80^{\circ} \mathrm{C}, 2-12 \mathrm{~h}$

$$
\begin{aligned}
& \text { 53a } R=H(67 \%) \\
& \text { 53b } R=M e(61 \%) \\
& \text { 53c } R=P h(58 \%) \\
& \text { 53d } R=2 \text {-pyridyl (55\%) }
\end{aligned}
$$

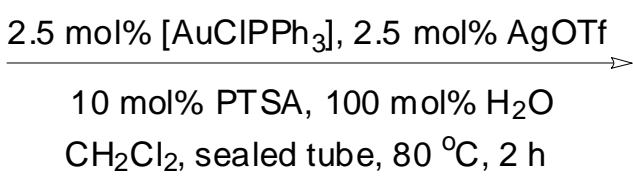

$54(58 \%)$

The challenging enantiopure alkynyloxazolidine-tethered 2-azetidinones 55-57 were tested as cyclization precursors. Remarkably, Scheme 19 shows how the mild conditions of gold catalysis allow the chemoselective formation of anellated $\beta$-lactams without harming the sensitive fourmembered ring. Using the terminal alkynes 55 the system $\mathrm{Au}(\mathrm{OTf}) \mathrm{PPh}_{3}$ gave the desired tricyclic bridged $\mathrm{N}, \mathrm{O}$-aminals 58 as the sole isomers in reasonable yields. Next, the reactivity of nonterminal alkynes 56 was investigated. Worthy of note, substituted and unsubtituted 2-azetidinonetethered alkynes at the terminal position followed different reactivity patterns. These results show that the oxygen atom participates in the first cyclization to form a fused eight-membered ring, which is not followed by the second cyclization of the NBoc group. Significantly, in contrast to the gold-catalyzed reaction of terminal alkynyloxazolidines 55 which lead to the 6-oxa-3,8- 
diazabicyclo[3.2.1]octane derivatives 58 via a 7-exo/5-exo bis-heterocyclization of the oxazolidine group towards the internal alkyne carbon (proximal adducts), the reaction of substituted at the terminal end alkynyloxazolidines 56 under identical conditions gave the 1,5-oxazocine derivatives 59 (distal adducts) as the sole products (Scheme 19), through an exclusive 8-endo oxycyclization by attack of the oxygen atom to the external alkyne carbon. Notably, when alkyne substituent was moved from position $\mathrm{N} 1$ to $\mathrm{C} 3$, as in 3,4-tethered alkynyloxazolidines 57 it furnished the corresponding bridged adducts $\mathbf{6 0}$ in fair yields and as only one isomer in its reaction with the gold catalytic system (Scheme 18). The precious metal-catalyzed 8-exo/5-exo bis-heterocyclization of alkynyloxazolidines 57 gave tricyclic bridged $\mathrm{N}, \mathrm{O}$-aminals $\mathbf{6 0}$ bearing a seven-membered ring (Scheme 19).

Scheme 19. Gold-catalyzed preparation of bridged azaoxa- $\beta$-lactams 58 and 60.<smiles>[R]OC1([2H])C(=O)N(CC#C)[C@H]1C1COC(C)(C)N1C(=O)O</smiles>

$55 \mathrm{a} R=\mathrm{Me}$

$55 b \mathrm{R}=\mathrm{Bn}$<smiles>[R]C#CCN1C(=O)[C@H](OC)[C@H]1C1COC(C)(C)N1C(=O)OCc1ccccc1</smiles>

$56 a \mathrm{R}=\mathrm{Ph}$

56b R = 2-thiophenyl

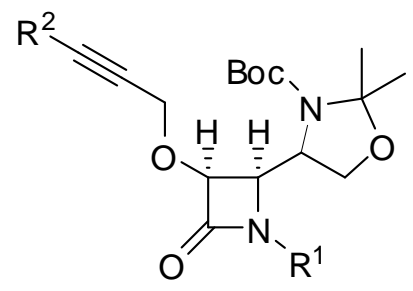

$57 a \mathrm{R}^{1}=\mathrm{PMP}, \mathrm{R}^{2}=\mathrm{H}$

$57 b^{1}=B n, R^{2}=H$

57c $\mathrm{R}^{1}=\mathrm{PMP}, \mathrm{R}^{2}=\mathrm{Me}$
2.5 mol\% [AuClPPh 3 ], 2.5 mol\% AgOTf

10 mol\% PTSA, 100 mol\% $\mathrm{H}_{2} \mathrm{O}$

$\mathrm{CH}_{2} \mathrm{Cl}_{2}$, sealed tube, $80{ }^{\circ} \mathrm{C}, 2 \mathrm{~h}$

$\underset{2.5 \mathrm{~mol} \%\left[\mathrm{AuClPPh}_{3}\right], 2.5 \mathrm{~mol} \% \mathrm{AgOTf}}{10 \mathrm{~mol} \% \mathrm{PTSA}, 100 \mathrm{~mol} \% \mathrm{H}_{2} \mathrm{O}}$

$\mathrm{CH}_{2} \mathrm{Cl}_{2}$, sealed tube, $80^{\circ} \mathrm{C}, 2 \mathrm{~h}$

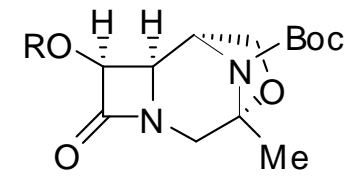

58a $R=\operatorname{Me}(58 \%)$

58b $\mathrm{R}=\mathrm{Bn}(60 \%)$

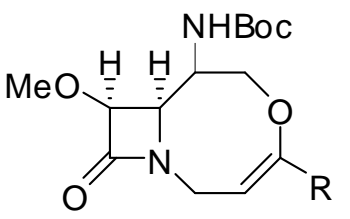

59a $\mathrm{R}=\mathrm{Ph}(57 \%)$

59b R = 2-thiophenyl (55\%)

$2.5 \mathrm{~mol} \%$ [AuClPPh 3 ], $2.5 \mathrm{~mol} \%$ AgOTf

10 mol\% PTSA, 100 mol\% $\mathrm{H}_{2} \mathrm{O}$

$\mathrm{CH}_{2} \mathrm{Cl}_{2}$, sealed tube, $80{ }^{\circ} \mathrm{C}, 2 \mathrm{~h}$

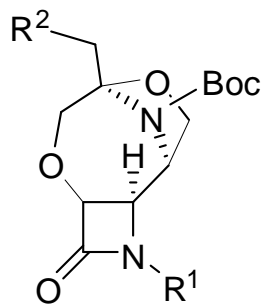

60a $\mathrm{R}^{1}=\mathrm{PMP}, \mathrm{R}^{2}=\mathrm{H}(62 \%)$

60b $\mathrm{R}^{1}=\mathrm{Bn}, \mathrm{R}^{2}=\mathrm{H}(75 \%)$

60c $\mathrm{R}^{1}=\mathrm{R}^{1}=\mathrm{PMP}, \mathrm{R}^{2}=\operatorname{Me}(50 \%)$ 
A possible pathway for the gold-catalyzed alkynyloxazolidine cyclization may initially involve the formation of a $\pi$-complex $\mathbf{6 1}$ through coordination of the gold salt to the triple bond of alkynyloxazolidines 55-57. Next, 7-exo oxymetalation forms zwitterionic enol vinylmetal species 62. Intermediates 62 did evolve through demetalation and oxazolidine hydrolysis forming methylenic oxacycles 63 and releasing the metal catalyst into the first catalytic cycle. Methylenic oxacycles 63 enter the second catalytic cycle generating species 64 by coordination of the alkene group with the metal; thus, enhancing the electrophilicity of the resulting enol ether. Subsequent intramolecular nucleophilic attack of the nitrogen to the more substituted alkene position would form the ate complex 65. Demetalation linked to proton transfer liberate adducts $\mathbf{5 8}$ and $\mathbf{6 0}$ with concomitant regeneration of the gold catalyst, closing the second catalytic cycle (Scheme 20). ${ }^{27}$

Scheme 20. Mechanistic explanation for the gold-catalyzed bis(heterocyclization) of alkynyloxazolidines.

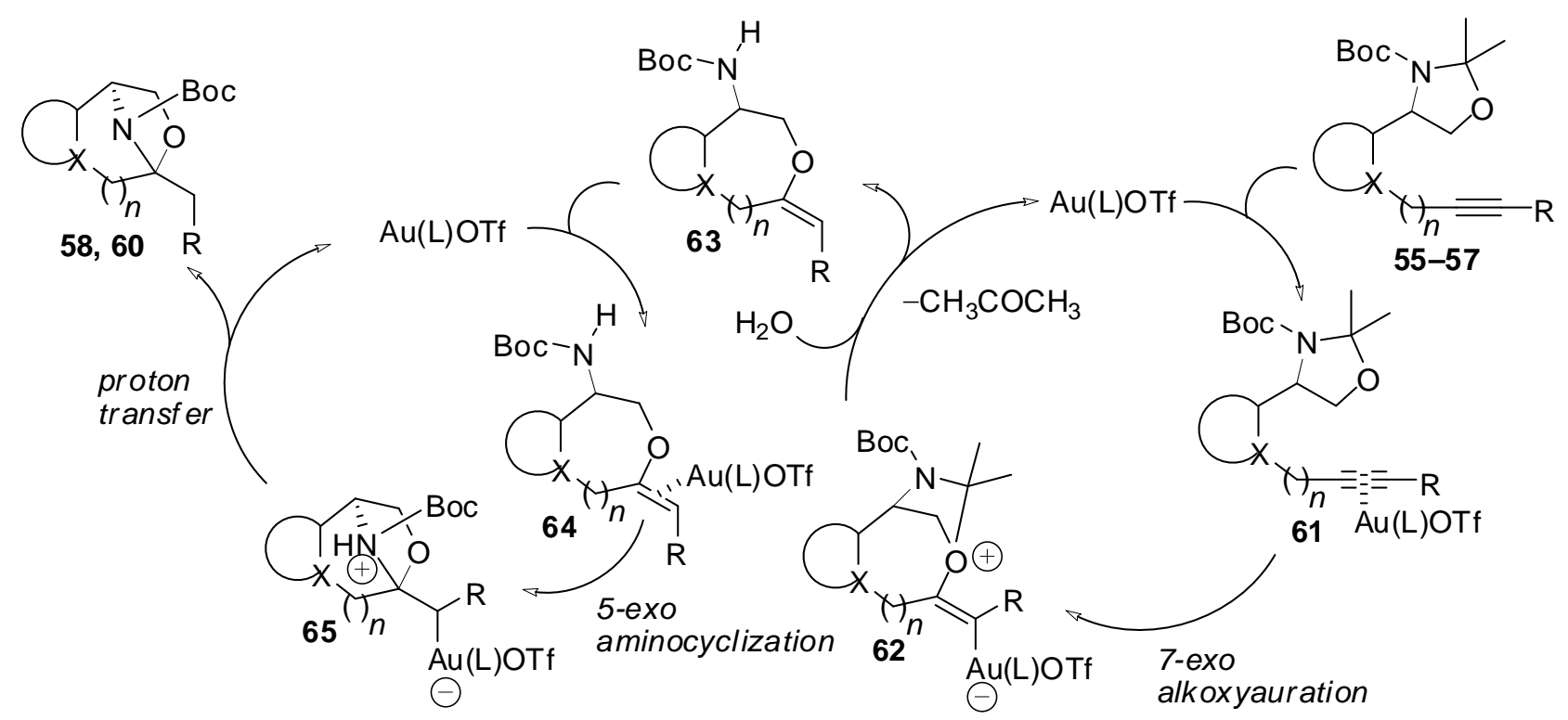

\section{Gold-catalyzed rearrangement of propargylic hydroperoxides}

After the contribution by Hashmi on the formation of hydroperoxides by a one-pot sequence of gold-catalyzed isomerization/autoxidation, ${ }^{28}$ we described the first report on the gold-catalyzed reactivity of alkynes bearing a hydroperoxide moiety. ${ }^{29}$ As shown in Scheme 21, the above process in a one-pot operation from readily available alkynyl hydroperoxides $\mathbf{6 6}$ and alcohols (methanol, ethanol, ethylene glycol) serves as a general approach to $\beta$-alkoxy ketones 67 . When we 
investigated the reactivity of propargylic hydroperoxides $\mathbf{6 6}$ with phenols at room temperature the starting materials were recovered. Only after heating at reflux temperature, the gold-catalyzed reactions evolved. Notably, the use of substituted phenols including catechol did not result in the formation of the corresponding phenoxy ketones; arylketones $\mathbf{6 8}$ were obtained instead as the result of a hydroarylation reaction (Scheme 21). Interestingly, compounds $\mathbf{6 8}$ were exclusively isolated as the para-substituted phenol regioisomers. Worthy of note, secondary alkynyl hydroperoxides also undergo these interesting transformations.

Scheme 21. Controlled gold-catalyzed reaction of propargylic hydroperoxides with alcohols and phenols.

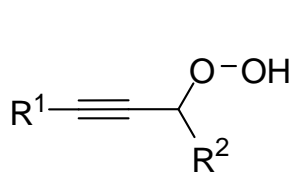

66
$2.5 \mathrm{~mol} \%\left[\mathrm{AuClPPh}_{3}\right.$ ], $2.5 \mathrm{~mol} \% \mathrm{AgOTf}$

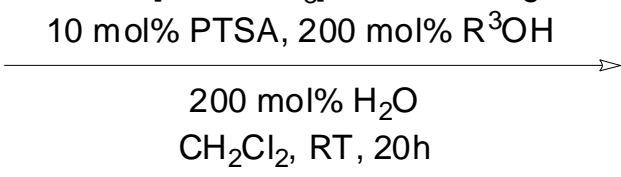

$\mathrm{CH}_{2} \mathrm{Cl}_{2}, \mathrm{RT}, 2 \mathrm{~h}$<smiles>[R]OC([R])CC([R])=O</smiles>

$67(57-80 \%)$

$\mathrm{R}^{1}=\mathrm{Ph}, 4-\mathrm{MeOC}_{6} \mathrm{H}_{4}, 4-\mathrm{BrC}_{6} \mathrm{H}_{4}$, 2-thiophenyl, $\mathrm{CH}_{2} \mathrm{OBn}$

$\mathrm{R}^{2}=\mathrm{H}, \mathrm{Me}$

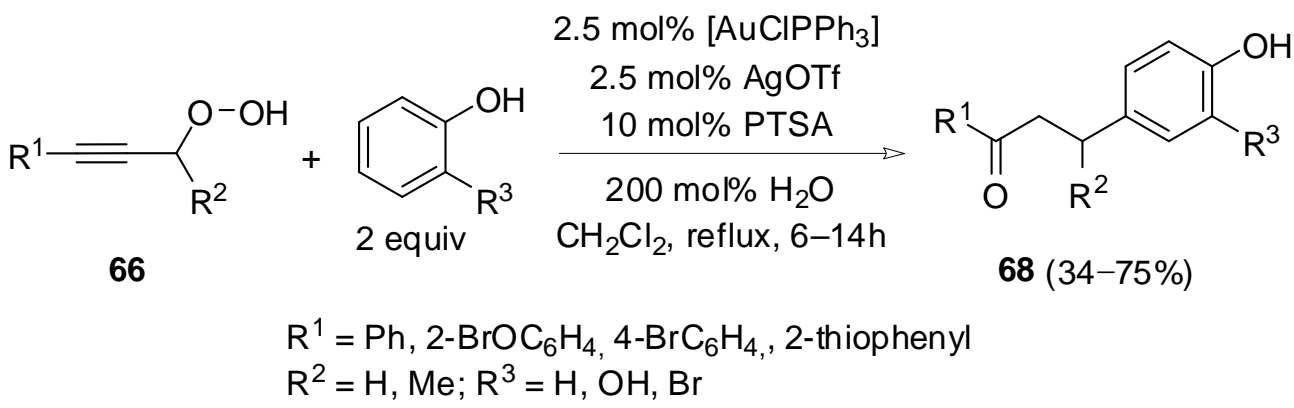

The reaction of propargylhydroperoxides to yield $\beta$-funtionalized ketones may be catalyzed by the $\mathrm{Au}(\mathrm{I})$ salt. The catalytic reaction is likely divided into five parts. Firstly, coordination of the carbon-carbon triple bond of propargylic hydroperoxides 66 to the Au(I) salt gives gold- $\pi$-alkynyl complex 66-Au. Species 66-Au evolves through a 1,3-hydroperoxide transposition to intermediate 69. Regioselective nucleophilic addition of water to the disubstituted allene double bond in goldallenyl complex 69 to give intermediate 70, followed by loss of hydrogen peroxide provides the $\alpha, \beta$-unsaturated ketonic gold complex 71. Next, 1,4-addition of the corresponding external nucleophile to the species 71, would form the gold intermediate 72. Demetalation linked to proton 
transfer provides final products $\mathbf{6 7}$ and $\mathbf{6 8}$ and regenerates the gold catalyst, closing the catalytic cycle (Scheme 22).

Scheme 22. Mechanistic explanation for the gold-catalyzed controlled preparation of $\beta$-functionalized ketones.

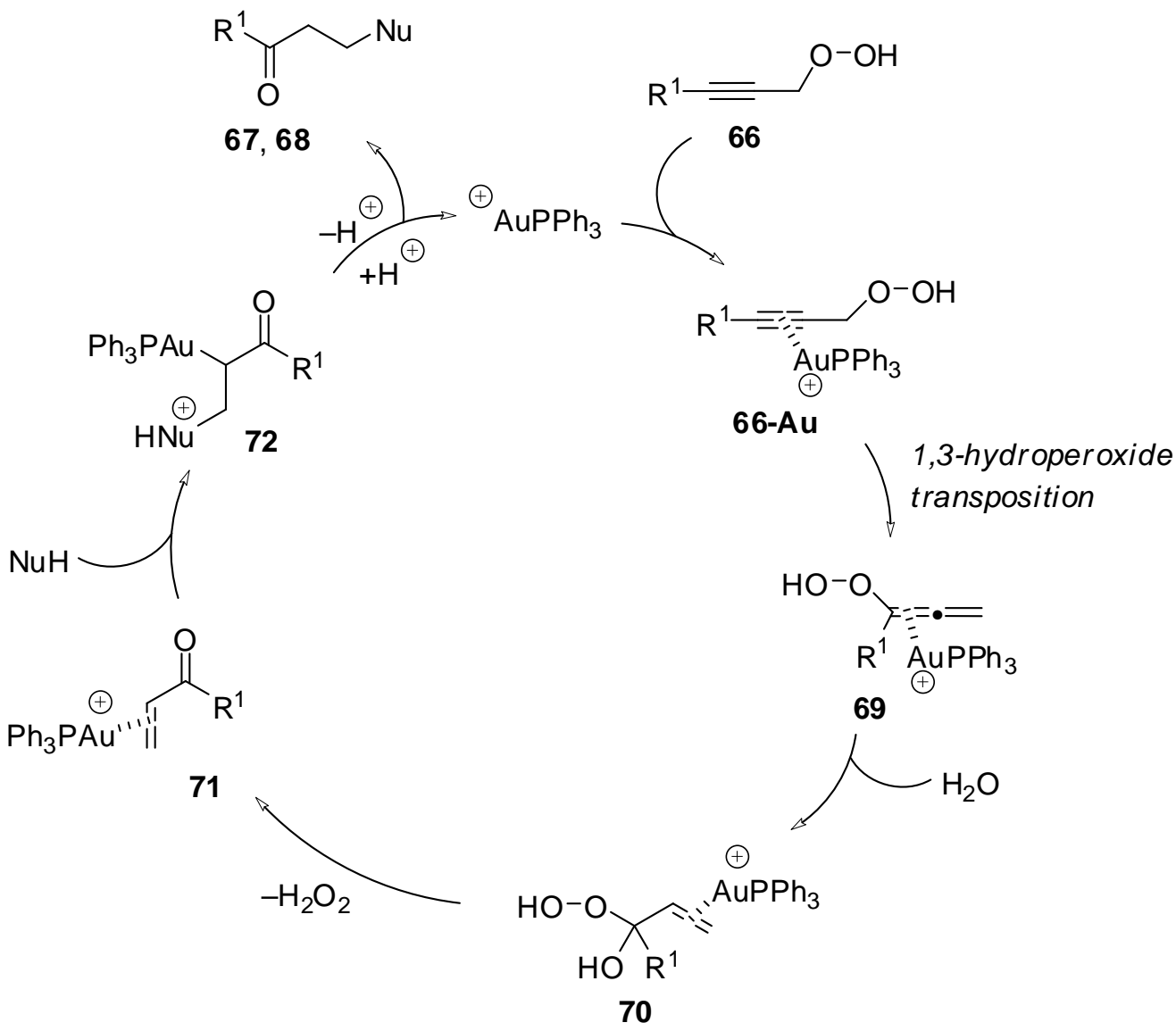

\section{Conclusions}

The last few years have witnessed dramatic growth in the number of reactions catalyzed by gold complexes because of their powerful soft Lewis acidic nature. This Account has reviewed selected examples from our group to illustrate certain advances in homogeneous gold catalysis for various types of organic transformations, focusing on the formation of $\mathrm{C}-\mathrm{C}$ and $\mathrm{C}-\mathrm{O}$ bonds using allenes and alkynes as starting materials.

Acknowledgment. Support for this work by the MINECO (Projects CTQ2012-33664-C02-01 and CTQ2012-33664-C02-02) and Comunidad Autónoma de Madrid (Project S2009/PPQ-1752) are gratefully acknowledged. 


\section{BIOGRAPHICAL INFORMATION}

Benito Alcaide received his B.S. degree and Ph.D. degree from the Universidad Complutense de Madrid (UCM). In 1984 he assumed a position of Associate Professor of Organic Chemistry and in 1990 was promoted to Full Professor at the UCM. His current recent interests include $\beta$-lactam chemistry, metal-promoted reactions, and organocatalysis.

Pedro Almendros received his B.S. degree and his Ph. D. degree from the Universidad de Murcia. After three postdoctoral years (University of Manchester), he joined the UCM. Currently he is Investigador Científico (Research Scientist) at the IQOG, CSIC, Madrid. His research interest includes allene chemistry, metal-promoted heterocyclizations, and $\mathrm{C}-\mathrm{C}$ coupling reactions.

\section{FOOTNOTES}

To whom correspondence should be addressed. E-mail: alcaideb@quim.ucm.es; Palmendros@iqog.csic.es.

The authors declare no competing financial interest.

\section{References and Notes}

1 (a) Haruta, M.; Yamada, N.; Kobayashi, T.; Iijima, S. Gold Catalysts Prepared by Coprecipitation for Low-Temperature Oxidation of Hydrogen and of Carbon Monoxide. J. Catal. 1989, 115, 301. (b) Hutchings, G. J. Vapor Phase Hydrochlorination of Acetylene: Correlation of Catalytic Activity of Supported Metal Chloride Catalysts. J. Catal. 1985, 96, 292.

2 (a) Oliver-Meseguer, J.; Cabrero-Antonino, J. R.; Domínguez, I.; Leyva-Pérez, A.; Corma, A. Small Gold Clusters Formed in Solution Give Reaction Turnover Numbers of $10^{7}$ at Room Temperature. Science 2012, 338, 1452. (b) Hashmi, A. S. K. Sub-Nanosized Gold Catalysts. Science 2012, 338, 1434.

3 Teles, J. H.; Brode, S.; Chabanas, M. Cationic Gold(I) Complexes: Highly Efficient Catalysts for the Addition of Alcohols to Alkynes. Angew. Chem. Int. Ed. 1998, 37, 1415. 
4 Ito, Y.; Sawamura, M.; Hayashi, T. Catalytic Asymmetric Aldol Reaction: Reaction of Aldehydes with Isocyanoacetate Catalyzed by a Chiral Ferrocenylphosphine-gold(I) Complex. J. Am. Chem. Soc. 1986, 108, 6405.

5 For selected recent reviews, see: (a) Hashmi, A. S. K.; Hutchings, G. J. Gold Catalysis. Angew. Chem. Int. Ed. 2006, 45, 7896. (b) Rudolph, M.; Hashmi, A. S. K. Gold catalysis in total synthesis - an update. Chem. Soc. Rev. 2012, 41, 2448. (c) Corma, A.; Leyva-Pérez, A.; Sabater, M. J. Gold-Catalyzed Carbon-Heteroatom Bond -Forming Reactions. Chem. Rev. 2011, 111, 1657. (d) Alcaide, B.; Almendros, P.; Alonso, J. M. Gold Catalyzed Oxycyclizations of Alkynols and Alkyndiols. Org. Biomol. Chem. 2011, 9, 4405. (e) Hashmi, A. S. K. Homogeneous Gold Catalysis Beyond Assumptions and Proposals-Characterized Intermediates. Angew. Chem. Int. Ed. 2010, 49, 5232.

6 For leading references on alkynes and allenes, see: (a) Science of Synthesis; Thomas, E. J., Ed.; Thieme: Stuttgart, 2008; Vol. 43. (b) Acetylene Chemistry; Diederich, F.; Stang, P. J.; Tykwinski, R. R., Eds.; Wiley-VCH: New York, 2005. (c) Yu, S.; Ma, S. Allenes in Catalytic Asymmetric Synthesis and Natural Product Syntheses. Angew. Chem. Int. Ed. 2012, 51, 3074. (d) Krause, N.; Winter, C. Gold-Catalyzed Nucleophilic Cyclization of Functionalized Allenes: A Powerful Access to Carbo- and Heterocycles. Chem. Rev. 2011, 111, 1994.

7 For the first paper, see: (a) Ferrer, C.; Echavarren, A. M. Gold-Catalyzed Intramolecular Reaction of Indoles with Alkynes: Facile Formation of Eight-Membered Rings and an Unexpected Allenylation. Angew. Chem. Int. Ed. 2006, 45, 1105. For selected very recent use, see: (b) Hashmi, A. S. K.; Yang, W.; Rominger, F. Gold-Catalysis: Highly Efficient and Regio-Selective Carbonyl Migration in Alkynyl-Substituted Indole-3-Carboxamides Leading to Azepino[3,4-b]indol-1-ones. Adv. Synth. Catal. 2012, 354, 1273.

8 (a) Alcaide, B.; Almendros, P.; Alonso, J. M.; Quirós, M. T.; Gadziński, P. Gold- or Palladium-Catalyzed Allene Carbocyclization/Functionalization: Simple and Efficient Synthesis of Carbazoles. Adv. Synth. Catal. 2011, 353, 1871. (b) W. Kong, C. Fu, S. Ma, General Au-Catalyzed Benzannulation Towards Naturally Occurring Carbazole Alkaloids from Methoxypropadiene. Chem. Eur. J. 2011, 17, 13134. (c) Alcaide, B.; Almendros, P.; 
Alonso, J. M.; Fernández, I. Carbocyclization versus Oxycyclization on the Metal-Catalyzed Reactions of Oxyallenyl C3-Linked Indoles. J. Org. Chem. 2013, 78, 6688.

9 (a) Hoffmann-Röder, A.; Krause, N. Gold(III) Chloride Catalyzed Cyclization of $\alpha$ Hydroxyallenes to 2,5-Dihydrofurans. Org. Lett. 2001, 3, 2537. (b) Hashmi, A. S. K.; Blanco, M. C.; Fischer, D.; Bats, J. W. Gold Catalysis: Evidence for the In-situ Reduction of Gold(III) During the Cyclization of Allenyl Carbinols Eur. J. Org. Chem. 2006, 1387.

10 Alcaide, B.; Almendros, P.; Cembellín, S.; Martínez del Campo, T.; Fernández, I. GoldCatalysed Tuning of Reactivity in Allenes: 9-endo Hydroarylation versus Formal 5-exo Hydroalkylation. Chem. Commun. 2013, 49, 1282.

11 Alcaide, B.; Almendros, P.; Martínez del Campo, T.; Fernández, I. Fascinating Reactivity in Gold Catalysis: Synthesis of Oxetenes through Rare 4-exo-dig Allene Cyclization and Infrequent $\beta$-Hydride Elimination. Chem. Commun. 2011, 47, 9054.

12 Hashmi, A. S. K.; Schuster, A. M.; Litters, S.; Rominger, F.; Pernpointner, M. Gold Catalysis: 1,3-Oxazines by Cyclisation of Allene Amides. Chem. Eur. J. 2011, 17, 5661.

13 (a) Hashmi, A. S. K. Fire and Ice: A Gold(III) Monohydride. Angew. Chem. Int. Ed. 2012, 51, 12935. (b) Klatt, G.; Xu, R.; Pernpointner, M.; Molinari, L.; Hung, T. Q.; Rominger, F.; Hashmi, A. S. K.; Köppel, H. Are $\beta$-H-Eliminations or Alkene Insertions Feasible Elementary Steps in Catalytic Cycles Involving Gold(I) Alkyl Species or Gold(I) Hydrides? . Chem. Eur. J. 2013, 19, 3954.

14 (a) Alcaide, B.; Almendros, P.; Martínez del Campo, T. Metal-Catalyzed Regiodivergent Cyclization of $\gamma$-Allenols: Tetrahydrofurans versus Oxepanes. Angew. Chem. Int. Ed. 2007, 46, 6684. (b) Alcaide, B.; Almendros, P.; Martínez del Campo, T.; Soriano, E.; MarcoContelles, J. L. Regioselectivity Control in the Metal-Catalyzed O-C Functionalization of $\gamma$ Allenols. Theoretical Calculations Compared with Experimental Results. Part 1: Experimental Study. Chem. Eur. J. 2009, 15, 1901.

15 Alcaide, B.; Almendros, P.; Martínez del Campo, T.; Soriano, E.; Marco-Contelles, J. L. Regioselectivity Control in the Metal-Catalyzed O-C Functionalization of $\gamma$-Allenols. Theoretical Calculations Compared with Experimental Results. Part 2: Theoretical Study. Chem. Eur. J. 2009, 15, 1909. 
16 Alcaide, B.; Almendros, P.; Luna, A.; Prieto, N. Metal-Catalyzed Rearrangements of 3Allenyl 3-Hydroxyindolin-2-ones in the Presence of Halogenated Reagents. Org. Biomol. Chem. 2013, 11, 1216.

17 For the gold-catalyzed halogenation of arenes by $N$-bromosuccinimide to functionalize $\mathrm{C}-\mathrm{H}$ bonds, see: (a) Mo, F.; Yan, J. M.; Qiu, D.; Li, F.; Zhang, Y.; Wang, J. Gold-Catalyzed Halogenation of Aromatics by $N$-Halosuccinimides. Angew. Chem. Int. Ed. 2010, 49, 2028. (b) Hashmi, A. S. K.; Schuster, A. M.; Litters, S.; Rominger, F.; Pernpointner, M. Gold Catalysis: 1,3-Oxazines by Cyclisation of Allene Amides. Chem. Eur. J. 2011, 17, 5661.

18 (a) Taft, F.; Harmrolfs, K.; Nickeleit, I.; Heutling, A.; Kiene, M.; Malek, N.; Sasse, F.; Kirschning, A. Combined Muta- and Semisynthesis: A Powerful Synthetic Hybrid Approach to Access Target Specific Antitumor Agents Based on Ansamitocin P3. Chem. Eur. J. 2012, 18, 880. (b) Shpak-Kraievskyi, P.; Yin, B.; Martel, A.; Dhal, R.; Dujardin, G.; Laurent, M. Y. Access to $C$-Protected $\beta$-Amino-Aldehydes via Transacetalization of 6-Alcoxy Tetrahydrooxazinones and Use for Pseudo-Peptide Synthesis. Tetrahedron 2012, 68, 2179.

19 Robles-Machín, R.; Adrio, J.; Carretero, J. C. Gold-Catalyzed Synthesis of Alkylidene 2Oxazolidinones and 1,3-Oxazin-2-ones. J. Org. Chem. 2006, 71, 5023.

20 Alcaide, B.; Almendros, P.; Quirós, M. T.; Fernández, I. Gold-Catalyzed Oxycyclization of Allenic Carbamates: Expeditive Synthesis of 1,3-Oxazin-2-ones. Beilstein J. Org. Chem. 2013, 9, 818.

21 A. Hashmi, A. S. K.; Schuster, A. M.; Litters, S.; Rominger, F.; Pernpointner, M. Gold Catalysis: 1,3-Oxazines by Cyclisation of Allene Amides. Chem. Eur. J. 2011, 17, 5661.

22 (a) Barreiro, E. M.; Adrio, L. A.; Hii, K. K. (M.); Brazier, J. B. Coinage Metal Catalysts for the Addition of $\mathrm{O}-\mathrm{H}$ to $\mathrm{C}=\mathrm{C}$ Bonds. Eur. J. Org. Chem. 2013, 1027. (b) Rudolph, M.; Hashmi, A. S. K. Heterocycles from Gold Catalysis. Chem. Commun. 2011, 47, 6536. (c) Das, A.; Sohel, S. M. A.; Liu, R.-S. Carbo- and Heterocyclisation of Oxygen- and NitrogenContaining Electrophiles by Platinum, Gold, Silver and Copper Species. Org. Biomol. Chem. 2010, 8, 960. (d) Yamamoto, Y.; Gridnev, I. D.; Patil, N. T.; Jin, T. Alkyne Activation with Brønsted Acids, Iodine, or Gold Complexes, and its Fate Leading to Synthetic Application. Chem. Commun. 2009, 5075. (e) Kirsch, S. F. Construction of Heterocycles by the Strategic 
Use of Alkyne $\pi$-Activation in Catalyzed Cascade Reactions. Synthesis 2008, 3183. (f) McDonald, F. E. Alkynol endo-Cycloisomerizations and Conceptually Related Transformations. Chem. Eur. J. 1999, 5, 3103.

23 Alcaide, B.; Almendros, P.; Carrascosa, R.; Martínez del Campo, T. Metal-Catalyzed Cycloisomerization and Tandem Oxycyclization/Hydroxylation of Alkynols. Synthesis of Non-Fused, Spiranic, and Fused Oxabicyclic $\beta$-Lactams. Eur. J. Org. Chem. 2010, 4912.

24 (a) Antoniotti, S.; Genin, E.; Michelet, V.; Genêt, J.-P. Highly Efficient Access to Strained Bicyclic Ketals via Gold-Catalyzed Cycloisomerization of Bis-homopropargylic Diols. J. Am. Chem. Soc. 2005, 127, 9976. (b) Corma, A.; Ruiz, V. R.; Leyva-Pérez, A.; Sabater, M. J. Regio- and Stereoselective Intermolecular Hydroalkoxylation of Alkynes Catalysed by Cationic Gold(I) Complexes. Adv. Synth. Catal. 2010, 352, 1701.

25 (a) Alcaide, B.; Almendros, P.; Carrascosa, R.; Torres, M. R. Gold/Acid-Cocatalyzed Regiodivergent Preparation of Bridged Ketals via Direct Bis-Oxycyclization of Alkynic Acetonides. Adv. Synth. Catal. 2010, 352, 1277. (b) Alcaide, B.; Almendros, P.; Carrascosa, R. Gold-Catalyzed Direct Cycloketalization of Acetonide-Tethered Alkynes in the Presence of Water. Tetrahedron 2012, 68, 9391. (c) Alcaide, B.; Almendros, P.; Carrascosa, R.; López, R.; Menéndez, M. I. Gold-Catalyzed Bis-Cyclization of 1,2-Diol- or Acetonide-Tethered Alkynes. Synthesis of $\beta$-Lactam-Bridged Acetals: A Combined Experimental and Theoretical Study. Tetrahedron 2012, 68, 10748.

26 (a) Hashmi, A. S. K.; Bührle, M.; Wölfle, M.; Rudolph, M.; Wieteck, M.; Rominger, F.; Frey, W. Gold Catalysis: Tandem Reactions of Diyne-Diols and External Nucleophiles as an Easy Access to Tricyclic Cage-Like Structures. Chem. Eur. J. 2010, 16, 9846.

27 Alcaide, B.; Almendros, P.; Carrascosa, R. Straightforward Synthesis of Bridged Azaoxa Skeletons: Gold-Catalyzed Aminoketalization of Garner’s Aldehyde-Derived Alkynes. Chem. Eur. J. 2011, 17, 4968.

28 Hashmi, A. S. K.; Blanco Jaimes, M. C.; Schuster, A. M.; Rominger F. From Propargylic Amides to Functionalized Oxazoles: Domino Gold Catalysis/Oxidation by Dioxygen. J. Org. Chem. 2012, 77, 6394. 
29 Alcaide, B.; Almendros, P.; Quirós, M. T.; López, R.; Menéndez, M. I., Sochacka-Ćwikła, A. Unveiling the Reactivity of Propargylic Hydroperoxides under Gold Catalysis. J. Am. Chem. Soc. 2013, 135, 898.

Autores: Alcaide, B.; Almendros, P.

Título: Gold-Catalyzed Cyclization Reactions of Allenol and Alkynol Derivatives

Revista: Accounts Chem. Res. 2014, 47, 939-952 (número especial sobre “Gold Catalysis” editado por Cynthia M. Friend y A. Stephen K. Hashmi); DOI: 10.1021/ar4002558 